Review

\title{
Gastroretentive Technologies in Tandem with Controlled-Release Strategies: A Potent Answer to Oral Drug Bioavailability and Patient Compliance Implications
}

\author{
Napoleon-Nikolaos Vrettos, Clive J. Roberts (1) and Zheying Zhu * \\ School of Pharmacy, University of Nottingham, Nottingham NG7 2RD, UK; \\ napoleon.vrettos@nottingham.ac.uk (N.-N.V.); clive.roberts@nottingham.ac.uk (C.J.R.) \\ * Correspondence: zheying.zhu@nottingham.ac.uk; Tel.: +44-(0)115-9515031
}

check for

updates

Citation: Vrettos, N.-N.; Roberts, C.J.; Zhu, Z. Gastroretentive Technologies in Tandem with Controlled-Release Strategies: A Potent Answer to Oral Drug Bioavailability and Patient Compliance Implications. Pharmaceutics 2021, 13, 1591. https://doi.org/10.3390/ pharmaceutics13101591

Academic Editor:

Marta González-Álvarez

Received: 8 August 2021

Accepted: 27 September 2021

Published: 30 September 2021

Publisher's Note: MDPI stays neutral with regard to jurisdictional claims in published maps and institutional affiliations.

Copyright: (c) 2021 by the authors. Licensee MDPI, Basel, Switzerland. This article is an open access article distributed under the terms and conditions of the Creative Commons Attribution (CC BY) license (https:// creativecommons.org/licenses/by/ $4.0 /)$.

\begin{abstract}
There have been many efforts to improve oral drug bioavailability and therapeutic efficacy and patient compliance. A variety of controlled-release oral delivery systems have been developed to meet these needs. Gastroretentive drug delivery technologies have the potential to achieve retention of the dosage form in the upper gastrointestinal tract (GIT) that can be sufficient to ensure complete solubilisation of the drugs in the stomach fluids, followed by subsequent absorption in the stomach or proximal small intestine. This can be beneficial for drugs that have an "absorption window" or are absorbed to a different extent in various segments of the GIT. Therefore, gastroretentive technologies in tandem with controlled-release strategies could enhance both the therapeutic efficacy of many drugs and improve patient compliance through a reduction in dosing frequency. The paper reviews different gastroretentive drug delivery technologies and controlled-release strategies that can be combined and summarises examples of formulations currently in clinical development and commercially available gastroretentive controlled-release products. The different parameters that need to be considered and monitored during formulation development for these pharmaceutical applications are highlighted.
\end{abstract}

Keywords: stomach; absorption window; gastric retention; gastroretentive drug delivery systems; controlled release; patient compliance

\section{Introduction}

Oral drug delivery systems are the most popular dosage forms for drug administration [1,2]. Many reasons contribute to their dominance, including high patient compliance, easy storage and transportation, cost-effectiveness and that no specialised medical personnel are required to administer. However, poor bioavailability can be an issue for many orally delivered drugs with $\mathrm{pH}$-dependent solubility or stability or a narrow window of absorption. Such properties need to be considered during formulation development since they could cause incomplete drug absorption when the dosage form is transferred towards the lower part of the gastrointestinal tract (GIT) [3-5].

Gastroretentive drug delivery systems (GRDDS) were developed as a new approach for the oral controlled-release delivery of many drugs [6-9]. These systems can be retained in the stomach long enough to completely release the active drug from a formulation in the gastric fluids. Their application comes with several advantages, including improved absorption of drugs and reduced fluctuation in drug blood levels that lead to increased therapeutic efficacy and minimised adverse effects, as well as their potential to enable stomach-specific activity. These systems can ensure the controlled delivery of drugs for an extended period at the desired rate and absorption site [5,10-12]. Suitable candidates for GRDDS include drugs with poor absorption in the distal GIT, a narrow absorption window in the proximal small intestine, stability and/or solubility issues at alkaline intestinal $\mathrm{pH}$, a 
short half-life and/or a local activity at the upper part of the intestine for the eradication of Helicobacter pylori $[9,13-21]$.

GRDDS can either be controlled-release systems intrinsically or coupled with such technologies to ensure a controlled release of drugs. Controlled-release applications promote enhanced patient compliance to the treatment, due to less frequent administration, and minimised adverse effects, thereby promoting therapeutic efficacy [22-27].

Several strategies have been developed for gastric retention purposes. These include floating systems $[13,14,16]$, high-density systems, bio/mucoadhesive [19,20,28-31], expandable [15], superporous hydrogels [32,33] and magnetic systems [34-36].

Different formulation-related factors can affect the quality and performance of the gastroretentive dosage form in terms of both gastric retention and controlled drug release. These include polymer types (non-ionic, cationic and anionic polymers), polymer composition in dosage form, viscosity grade, molecular weight of the polymer(s) that are used in the formulation, as well as drug solubility [16]. The size and density of gastroretentive systems can also be very important. Depending on the type of gastroretentive technology, it can either ensure a controlled release of active pharmaceutical ingredients (APIs) alongside gastric retention or it can be combined with a controlled-release strategy to ensure the release of drugs over the desired period.

This review examines the different gastroretentive drug delivery technologies available in the market and those reported in the literature, as well as their potential to ensure a controlled release of APIs either as standalone systems or coupled with controlled-release strategies. The potential and future of these combinatory applications are also discussed.

\section{The Stomach}

The stomach (Figure 1) is a hollow, muscular organ located in the left upper quadrant of the peritoneal cavity [37]. Its role is to mix the orally ingested contents coming to the proximal stomach via the oesophagus, crossing the gastro-oesophageal junction ("cardia"), to form a chyme [38]. The distal stomach is connected to the duodenum and, the passage from the stomach to the duodenum is controlled by a muscular ring, i.e., the 'pyloric sphincter' or 'pylorus' [39]. The stomach is anatomically divided into three distinct regions: (i) the "fundus", situated to the upper left of the cardia and is the proximal part of the stomach; (ii) the "body", which lies between the fundus and the distal stomach ("antrum") and is the biggest part of the stomach and (iii) the "antrum", which constitutes the distal part of the stomach, ranging from the incisura angularis to the pylorus $[38,40]$. The body acts as a reservoir for undigested food materials, while the antrum acts as a pump aiming at assisting in gastric emptying of food particles through the pyloric sphincter via propelling actions. The antrum is the main mixing compartment of the stomach [41].

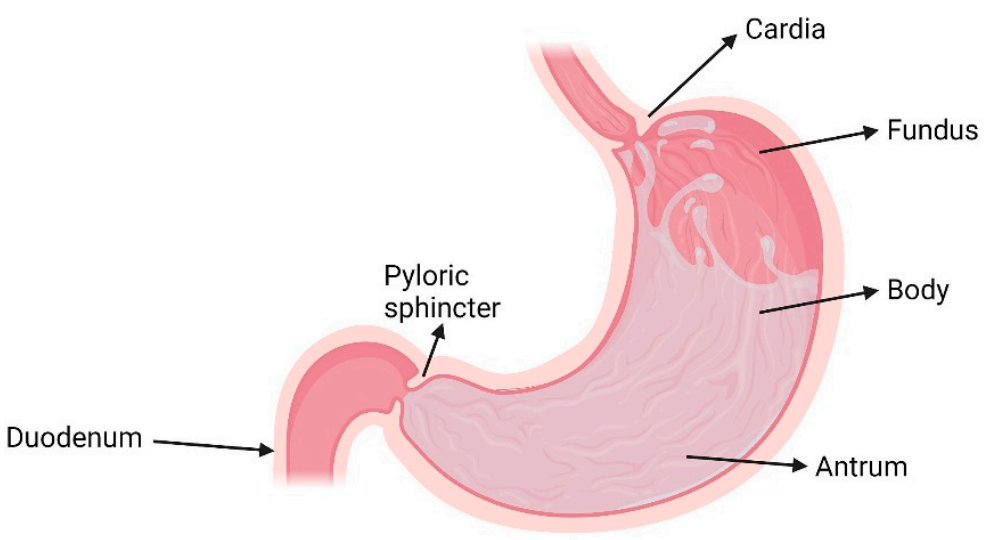

Figure 1. The human stomach. The figure was created using BioRender (www.biorender.com) (accessed on 2 August 2021). 
Gastric emptying occurs during both fasted and fed states. In the fasted state, the mobility of the stomach is controlled by the migrating myoelectric complex (MMC), which is a series of events occurring in a cyclic manner that lasts for about $2-3 \mathrm{~h}[42,43]$. The MMC consists of four phases. Phase I includes rare contraction waves and lasts for about 30-60 min. Phase II is comprised of contractions of increasing intensity and frequency as time passes. This phase lasts for 20-40 min. Phase III lasts for 10-20 min and is characterised by intense, regular contractions that push the undigested materials through the pyloric sphincter and into the small intestine. For this reason, Phase III is also termed "housekeeper wave". Finally, Phase IV includes a short transitional phase from Phase III to Phase I and lasts about 0-5 min [9]. This cycle is disrupted during the fed state, where the gastric emptying rate is lower. The motor activity is induced 5-10 min after ingestion and usually lasts 2-6 h, depending on the amount and caloric content of food [9].

As per Wickham et al., "Food in the stomach is usually a masticated mixture of protein, fat, carbohydrate, indigestible components, micronutrients, non-nutrient phytochemicals, microbiota, and water to which has been added a variable amount of saliva containing enzymes, salts, and bacteria. As such, the gastric food bolus is inhomogeneous at many different levels and retains, at least to some extent, the original structures of the foods consumed" [44]. Without the presence of food, the $\mathrm{pH}$ of the stomach is strongly acidic ( $\mathrm{pH} 2.0$ ) due to the presence of residual gastric secretions in the lowest part of the stomach the volume of which can be usually up to $50 \mathrm{~mL}$. When food becomes increasingly present in the stomach, while the stomach wall $\mathrm{pH}$ may remain acidic, there is a rise in the stomach bulk $\mathrm{pH}$ towards that of the food mixture due to its high buffering capacity. The presence of food generates a rapid transition of gastric contractions while gastric emptying begins, with its rate varying, depending on meal properties, such as size, composition, viscosity, temperature, and osmolarity [44].

The strength of the contractions rises from the fundus to the antrum which is the mixing and pumping component of the stomach. Due to the higher shear and mixing conditions in the antrum, the contents there tend to be more homogeneous than in the main body; however, due to differences in the nature of chewed food items, a complete homogeneity of the antrum content is unlikely, unless food is in a liquid form [44].

When gastroretentive drug delivery systems are administered in the fasted state, the MMC may be in any of its phases. This can significantly affect the gastric retention time (GRT) of the systems [9].

\section{Factors Affecting the Efficacy of GRDDS}

Different factors can affect the performance of GRDDS. These can be categorised into formulation-related factors, physiological factors, and patient-related factors.

\subsection{Formulation-Related Factors}

It is important to understand the critical attributes of the different types of GRDDS that can affect their performance. In formulation design, a careful choice of excipients and polymers is necessary to ensure effective gastric retention. Swelling polymers which reduce dosage form density, such as hydroxypropylmethylcellulose (HPMC) and polyethylene oxide (PEO), are effective in achieving prolonged buoyancy and enabling floatation $[45,46]$. Polymers with strong mucoadhesive properties, such as Carbopol ${ }^{\circledR}$ and chitosan, can assist gastric retention of the dosage form on the stomach wall $[47,48]$. In addition, other excipients that can also affect the system performance need to be considered, such as gas-generating agents for effervescent floating dosage forms and materials with swelling properties for superporous hydrogel systems.

The size and shape of the dosage form are also important parameters that can affect the performance of GRDDS. Gastric emptying occurs via the pyloric sphincter which has been reported to have a diameter of $(12.8 \pm 7) \mathrm{mm}$ [46]. It is generally accepted that a dosage form size larger than $15 \mathrm{~mm}$ is required for effective gastric retention [9]. The ability of single-unit dosage forms to avoid premature evacuation from the stomach can be variable 
and this constitutes a major drawback for these systems. More usefully, multiple-unit systems, such as microparticle-based formulations, tend to be evacuated in a linear manner from the stomach or as a bolus at the end of digestion, thus providing a more reliable gastric retention and drug release behaviour [49]. Considering dosage form shape, tetrahedronand ring-shaped dosage forms tend to have longer GRTs than others $[10,50]$.

The density of the formulation is a critical factor for low- and high-density systems. The density of low-density systems should be lower than the estimated $1.004 \mathrm{~g} / \mathrm{cm}^{3}$ value of gastric fluids, to allow for their floatation in the stomach [46,51,52]. However, the buoyancy duration of low-density dosage forms can also be dependent on the rate of hydration of the formulation [53]. For high-density systems, density should be higher than that of the gastric contents to ensure an effective sinking in the bottom of the stomach and resistance to the peristaltic movements; $2.5 \mathrm{~g} / \mathrm{cm}^{3}$ is considered crucial for a prolonged GRT of these formulations [54].

\subsection{Physiological Factors}

Many studies have highlighted the importance of physiological factors in promoting or impeding the efficacy of GRDDS through affecting their gastric retention capability, including the amount, nature and caloric content of food, frequency of food intake, posture, sleep and physical activity [5,10,15,55-57]. During the fasted state, stomach mobility is controlled by the MMC which occurs cyclically. If the timing of formulation administration coincides with that of the MMC, then the GRT of the dosage form can be very low [58]. However, in the presence of food, the MMC and the housekeeper waves are disrupted, thus leading to a potentially prolonged GRT [10,41,59]. Furthermore, the administration of successive meals can increase gastric retention by $6-7 \mathrm{~h}$, compared to a single intake of a meal. An increase in the caloric density of a meal can significantly prolong the GRT of dosage forms, whether it is protein-rich or fat-rich $[56,58]$. The nature of calories seems to have a minor effect on GRT [60]. In addition to the above, food viscosity is considered to have a positive effect on GRT [61,62]. Posture can affect different GRDDS in different ways. An upright position favours floatation of low-density systems, however, it impedes gastric retention capability of high-density systems, because they remain continuously in the lower part of the stomach and peristaltic contractions can result in a faster gastric emptying rate $[5,10]$. In contrast, in a supine position, the GRT of the non-floating systems is prolonged, compared to that of the floating systems $[63,64]$. Finally, the concomitant administration of drugs that affect the mobility of the gastrointestinal tract, such as anticholinergics, opiates and prokinetic agents, can affect the GRT [58].

\subsection{Patient-Related Factors}

Patient-related factors on the efficacy of GRDDS include age, gender, health conditions and emotional state. People aged over 65 tend to demonstrate longer GRTs for the dosage forms [65]. Wang et al. demonstrated that gender could have a significant effect on gastric emptying time and luminal $\mathrm{pH}$ with females demonstrating slower gastric emptying rates than males [66], possibly related to the menstrual cycle which has demonstrated an influence on the gastrointestinal (GI) transit. Wald et al. reported the prolongation of GI transit time during the luteal phase of the menstrual cycle, compared to the follicular phase which could mean that the transit is retarded with increasing progesterone levels [67]. Additionally, different health conditions can have varying effects on the GRT of dosage forms. Patients with Parkinson's disease tend to have longer GRTs that may be accompanied by constipation [68]. In patients with diabetes mellitus, the gastric emptying rate seems to be significantly prolonged, compared to non-diabetic patients [69]. Finally, the emotional state of a patient seems to affect gastric emptying time. Patients with depression have demonstrated slower gastric emptying rates, while increased gastric emptying rates have been recorded in patients suffering from anxiety conditions $[5,55,59]$. 


\section{Gastroretentive Drug Delivery Technologies and Their Controlled-Release Applications}

There are a few different gastroretentive drug delivery approaches. These include floating, high-density, mucoadhesive/bioadhesive, expandable, superporous hydrogel and magnetic systems, as well as combinatory approaches of these technologies. Products based on gastroretentive technologies that are either under clinical trials or commercially available are summarised in Table 1.

Table 1. Gastroretentive products currently under clinical trials or available commercially.

\begin{tabular}{|c|c|c|c|c|}
\hline Delivery System & Brand Name & $\begin{array}{l}\text { Active Pharmaceutical } \\
\text { Ingredient }\end{array}$ & Phase & $\begin{array}{l}\text { Manufacturing } \\
\text { Company }\end{array}$ \\
\hline \multirow{2}{*}{$\begin{array}{l}\text { Hydrodynamically } \\
\text { Balanced }\end{array}$} & Madopar ${ }^{\circledR}$ & $\begin{array}{l}\text { Levodopa and } \\
\text { Benserazide }\end{array}$ & Commercial & Intec Pharma (Israel) \\
\hline & Valrelease $^{\circledR}$ & Diazepam & Commercial & Roche (UK) \\
\hline $\begin{array}{l}\text { Non-effervescent } \\
\text { floating tablet }\end{array}$ & Glucophage ${ }^{\circledR}$ XR & Metformin & Commercial & $\begin{array}{l}\text { Merck KGaA } \\
\text { (Germany) }\end{array}$ \\
\hline Effervescent floating & Cifran $^{\circledR}$ & Ciprofloxacin & Commercial & Ranbaxy (India) \\
\hline \multirow{3}{*}{ Raft-forming } & Liquid Gaviscon ${ }^{\circledR}$ & $\begin{array}{c}\text { Sodium bicarbonate } \\
\text { and Calcium carbonate }\end{array}$ & Commercial & $\begin{array}{l}\text { Reckitt Benckiser } \\
\text { Healthcare (UK) Ltd. }\end{array}$ \\
\hline & Gaviscon ${ }^{\circledR}$ Tablets & $\begin{array}{l}\text { Sodium bicarbonate } \\
\text { and Calcium carbonate }\end{array}$ & Commercial & $\begin{array}{c}\text { Reckitt Benckiser } \\
\text { Healthcare (UK) Ltd. }\end{array}$ \\
\hline & Topalkan $^{\circledR}$ & $\begin{array}{l}\text { Aluminium and } \\
\text { Magnesium }\end{array}$ & Commercial & $\begin{array}{c}\text { Pierre Fabre } \\
\text { Medicament (France) }\end{array}$ \\
\hline Mucoadhesive/Bioadhesive & Xifaxan $^{\circledR}$ & Rifaximin & Commercial & Lupin (India) \\
\hline \multirow{7}{*}{ Expandable } & $\begin{array}{c}\text { Accordion Pill }^{\circledR} \\
\text { Levodopa/Carbidopa }^{\text {A }}\end{array}$ & $\begin{array}{l}\text { Levodopa and } \\
\text { Carbidopa }\end{array}$ & Phase III Clinical Trials & Intec Pharma (Israel) \\
\hline & $\begin{array}{c}\text { Requip }^{\circledR} \mathrm{XL} \\
\text { (Geomatrix }^{\circledR} \text { technology) }\end{array}$ & Ropinirole & Commercial & GlaxoSmithKline (UK) \\
\hline & $\begin{array}{c}\text { Glumetza }^{\circledR} \\
\text { (Acuform }{ }^{\circledR} \text { technology) }\end{array}$ & Metformin & Commercial & Salix (USA) \\
\hline & $\begin{array}{c}\text { Nucynta }^{\circledR} \text { ER } \\
\text { (Acuform }{ }^{\circledR} \text { technology) }\end{array}$ & Tapentadol & Commercial & Depomed (USA) \\
\hline & $\begin{array}{c}\text { Gralise }^{\circledR} \\
\text { (Acuform }{ }^{\circledR} \text { technology) }\end{array}$ & Gabapentin & Commercial & Depomed (USA) \\
\hline & Janumet ${ }^{\circledR} \mathrm{XR}$ & $\begin{array}{l}\text { Sitagliptin and } \\
\text { metformin }\end{array}$ & Commercial & $\begin{array}{c}\text { Merck Sharp \& Dohme } \\
\text { (USA) }\end{array}$ \\
\hline & $\begin{array}{l}\text { LYN-005 (Long-acting } \\
\text { Pill technology) }\end{array}$ & Risperidone & Phase II Clinical Trials & $\begin{array}{c}\text { Lyndra }^{\circledR} \text { Therapeutics } \\
\text { (USA) }\end{array}$ \\
\hline Osmotic & Coreg $^{\circledR} \mathrm{CR}$ & Carvedilol Phosphate & Commercial & GlaxoSmithKline (UK) \\
\hline
\end{tabular}

\subsection{Floating Systems}

Floating systems are the most extensively studied gastroretentive dosage forms. The bulk density of such formulations is lower than $1.004 \mathrm{~g} / \mathrm{cm}^{3}$ which enables its buoyancy in the gastric fluids for an extended period while the drug is released (Figure 2) [5,10,41,70,71]. A major advantage of this approach is that dosage form floatation results in their presence not affecting the gastric motility or causing harm to the gastric mucosa [21,72]. This category includes non-effervescent floating systems, such as hydrodynamically balanced systems and non-effervescent tablets, effervescent floating systems and raft-forming systems. 


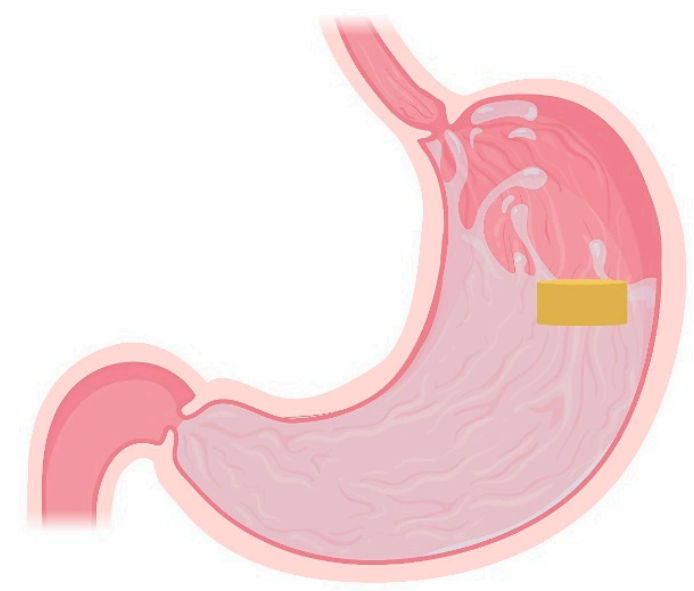

Figure 2. Intragastric location of the floating drug delivery systems. The figure was created using BioRender (https: / / www.biorender.com/) (accessed on 3 August 2021).

\subsubsection{Non-Effervescent Floating Systems}

In non-effervescent floating systems, highly swellable or gel-forming polymers are employed to achieve floatation. This category includes hydrodynamically balanced systems, floating tablets (single-layer or bilayer), and low-density systems (e.g., microballoons) [10]. The use of non-effervescent floating systems comes with notable advantages, including independence of the floating mechanism of variable gastric $\mathrm{pH}$ and avoiding problems in patients with achlorhydria. Furthermore, the exclusion of acidic and/or basic gas-generating agents can ensure a better stability of acid- or base-labile drugs, respectively [13].

- Hydrodynamically Balanced Systems

Hydrodynamically balanced systems (HBS) are single-unit dosage forms composed of one or more gel-forming hydrophilic polymers. The key element in the development of this form is the appropriate selection of hydrophilic polymer(s) to ensure adequate flotation and release of the drug [45]. These include HPMC, hydroxypropylcellulose (HPC), sodium carboxymethylcellulose, hydroxyethylcellulose, chitosan, tamarind, xanthan, carrageenan, agar, and alginic acid. These systems are mainly formulated in gelatin capsules [73-76]. In this approach, the drug is mixed with the gel-forming polymer which hydrates and swells upon contact with the fluids, thus maintaining the density of the system below $1 \mathrm{~g} / \mathrm{cm}^{3}$ [10] Hydrophilic polymers such as HPMC, PEO, HPC and cellulose acetate phthalate are the most commonly used. Madopar ${ }^{\circledR}$ HBS is a typical example of an HBS capsule, it contains a combination of levodopa and benserazide and is used for the treatment of Parkinson's syndrome. HPMC is used as the gel-forming polymer and hydrogenated vegetable oil as a low-density fatty excipient. Valrelease ${ }^{\circledR}$ is another example that contains diazepam as the API in a similar formulation and is used in patients suffering from anxiety, muscle spasms and seizures.

Since HBSs are single-unit dosage forms and gel-forming hydrophilic polymers are major components of this type of formulation, HBSs are by default controlled-release systems, as well as being gastroretentive. Hydrophilic polymers are used alone or in combinations to ensure tablet floatation and retard drug release. Dorożyński et al. developed a L-dopa HBS capsule formulation consisting of HPMC and different grades of carrageenan. It was shown that, while carrageenans were unable to retard the release of the API from the capsules for the desirable timeframe, they were able to provide flexibility in the properties of the polymeric matrices with the potential for developing tailor-made systems [45]. For controlled-release purposes, hydrophobic polymers and substances can also be included in HBS formulations to further retard the release of drugs. These include ethylcellulose or liquid paraffin [77]. Here, the increased retardation of drug release may be due to a reduced solvent penetration into the matrix due to the hydrophobic polymer, leading to reduced drug diffusion [78,79]. Furthermore, the inclusion of fatty excipients, such as hydrogenated 
vegetable oil, as well as giving low-density formulations also reduce the penetration of water, and thus reduce matrix erosion [80-82].

A drawback of HBS is that it is not possible to change the release kinetics of the drug without changing the floating behaviour of the system since it is a matrix comprised of a mix of the drug and low-density hydrophilic polymers [10]. As floatation behaviour is passive and has a strong dependence on the air sealed in the dry mass centre and the swelling of the polymer surface, changes in polymer amount significantly affect system behaviour [76]. To address this limitation, strategies have been proposed to improve the efficacy of HBS. Oth et al. developed a bilayer capsule formulation of misoprostol consisting of a buoyancy layer and a drug-containing layer. Both layers contained swellable polymers and this separation allowed for their independent optimisation. In vivo gamma scintigraphy studies were conducted and the capsules achieved gastric retention that lasted longer than $3 \mathrm{~h}$ after a single breakfast meal and longer than $10 \mathrm{~h}$ after administration of successive meals [83]. Additionally, Krögel and Bodmeier developed a system that consisted of an impermeable polypropylene cylinder that contained entrapped air in the centre, surrounded on both ends by matrix layers containing drug and HPMC (Figure 3) [84].

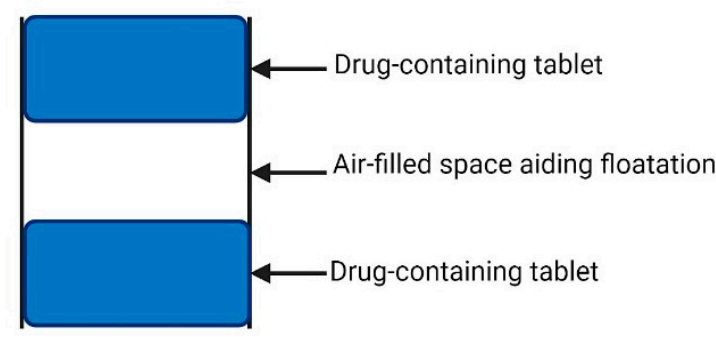

Figure 3. The polypropylene cylinder system developed by Krögel and Bodmeier [84]. The system consisted of entrapped air surrounded on both sides by drug-containing tablets. The air-filled space ensured a low density of the system, thus enabling its floatation. The figure was created using BioRender (www.biorender.com) (accessed on 2 August 2021).

\section{- $\quad$ Non-Effervescent Tablets}

Single-layer and bilayer floating tablets are another category of non-effervescent floating systems. For gastric retention, usually hydrophilic polymers such as HPMC, HPC, sodium alginate, $\mathrm{PEO}$ are used $[13,17,85-87]$.

Non-effervescent single-layer floating tablets have been reported in the literature and their use is associated with novel work. Like HBS, single-layer floating tablets combine both gastroretentive and controlled-release properties since the polymers are responsible for both tablet floatation and controlled drug release. Glucophage ${ }^{\circledR} \mathrm{XR}$ is an example of this type of gastroretentive formulation that contains metformin and is used to treat type 2 diabetes.

Hwang et al. developed highly porous cilostazol gastroretentive tablets using a manufacturing method that included a sublimation step. Menthol was incorporated into the tablets as the sublimating agent and, after compression, the tablets were placed in a vacuum oven for $12 \mathrm{~h}$, so that sublimation may occur. The resultant highly porous formulations floated immediately without any lag time, while the percolation threshold of HPMC was an important factor in determining the release mechanism of cilostazol [14]. Other formulation excipients can also affect the buoyancy behaviour of non-effervescent singlelayer tablets. Kim et al. developed pregabalin gastroretentive tablets containing HPMC, HPC and PEO as swelling hydrophilic polymers and demonstrated that the selection of a super-disintegrant, such as crospovidone, resulted in a prolonged tablet buoyancy, compared to using microcrystalline cellulose (MCC). The super-disintegrant is thought to have contributed to a significant expansion of the tablet volume upon contact with the dissolution media, compared to MCC which, due to its relatively weak disintegrant properties, absorbed water and hindered buoyancy [13]. 
Apart from hydrophilic polymers, hydrophobic materials and proteins, such as zein (an amphiphilic protein derived from corn), have also been used for gastric retention [88]. Raza et al. prepared single-layer tablets based on zein. L-menthol was used as a sublimating agent to provide tablets with inherent low density. The optimised formulation was able to float immediately and for $24 \mathrm{~h}$ in hydrochloric acid, whilst releasing the incorporated drug over the entire period. Furthermore, despite its high porosity, it was able to maintain a high mechanical strength after $12 \mathrm{~h}$ of dissolution [88]. Single-layer tablets containing stearyl alcohol as a floating-assistance material due to its low bulk density have also been reported [1,85], although sticking problems may hinder development [1]. In general, tabletability is a factor that needs to be considered when using fatty excipients [1].

Non-effervescent formulations have also been reported in the form of bilayer tablets. Bilayer tablets can be fixed-dose combinations (FDC) where a single dosing unit can contain two or more APIs in different layers [89]. Additionally, one layer can be an immediaterelease layer of a drug, while the other is a sustained-release layer of the drug which is also responsible for the floating of the tablet. In other cases, the tablet can be comprised of a drugfree gastroretentive layer and a sustained-release drug layer [21]. To avoid long floating lag times, low-density materials are used in the gastroretentive layer to achieve rapid buoyancy of tablets. Additionally, rapid buoyancy can result from low compression force values that allow for higher tablet porosity and lower tablet density and hence a rapid polymer wetting and swelling that further reduces the density of the dosage form [17]. Furthermore, materials such as camphor and L-menthol that can undergo sublimation may be used. These materials are sublimed upon tablet heating, leading to an increased tablet porosity and reduced density that enables tablets to float immediately $[14,88,90]$. Among these materials, camphor is the most frequently used. Nguyen et al. prepared gastroretentive bilayer tablets based on Kollidon ${ }^{\circledR}$ SR which was used in the gastroretentive layer along with camphor as a sublimation agent. Due to the inherently low density of Kollidon ${ }^{\circledR}$ SR and the improved wet strength of the gastroretentive layer linked to the presence of a hydrophobic polymer, along with the further reduction in the tablet density from camphor sublimation, a 12-h floating was successfully reached in vitro, even at a rotation rate of $200 \mathrm{rpm}$ [72]. This high paddle rotation speed is designed to create conditions that better simulate the in vivo conditions in fasted Beagle dogs, compared to typically used lower rotation speed values [72,91].

- Low-Density Systems

Most floating gastroretentive formulations tend to have a lag time prior to floating in stomach contents. During that time, a premature evacuation of the dosage form from the stomach may take place via the pyloric sphincter [9]. Low-density systems are formulations that have an inherent density lower than $1.004 \mathrm{~g} / \mathrm{cm}^{3}$ which enables their immediate floatation in the stomach. These include drug-loaded microballoons/hollow microspheres, sponges and are multiple-unit floating systems [92,93].

Microballoons have a low-density, hollow core, and are made of materials that can entrap oil or air [94-98]. Commonly used polymers in these systems are polycarbonate, calcium alginate, Eudragit ${ }^{\circledR}$ S, cellulose acetate, agar and low-methoxylated pectin. They can be prepared through simple solvent evaporation or solvent diffusion techniques [75]. Kawashima et al. prepared microballoons based on polyvinyl alcohol (PVA) and Eudragit ${ }^{\circledR}$ $S$ using an emulsion-solvent diffusion technique [94]. Eudragit ${ }^{\circledR} S$ formed a mechanically strong film (shell) on the outer surface of the microballoons which ensured the stability of the system during solvent evaporation and hindered drug release at $\mathrm{pH}$ values below 7 , due to solubility and permeability limitations of the polymer. The drug (tranilast or ibuprofen) was loaded into the outer shell of the microballoon. Around $90 \%$ of the microballoons floated on the surface of the hydrochloric acid medium, however, microballoons that lost buoyancy could pass from the stomach and still release the drug in a controlled manner in the upper small intestine which was the absorption site. Therefore, this multiple-unit system seemed to be versatile in achieving a prolonged residence time in the stomach, whilst providing a controlled drug release and ensuring a good bioavailability [94]. Further- 
more, Ammar et al. prepared cinnarizine microballoons based on cellulose acetate butyrate (CAB), a hydrophobic polymer that had not been used for this purpose before [99]. Due to the hydrophobic nature of the drug, it was able to be incorporated into the formulation in a sufficient amount. The in vitro release testing demonstrated a biphasic release of cinnarizine from the formulation that was probably due to availability of the drug on the surface of microballoons as well as the interior of the matrix. After $1 \mathrm{~h}$, the drug release rate slowed and was followed by a controlled-release phase linked to slow drug diffusion through the microballoon polymer structure. Increasing CAB concentration levels led to slower drug release rates, probably due to a more compact polymer structure, as well as poorer wetting of the microballoons derived from the hydrophobic nature of the polymer. Finally, a clinical trial in humans demonstrated a significantly prolonged release of cinnarizine in vivo, alongside higher $\mathrm{AUC}_{0-24 \mathrm{~h}}$ and $\mathrm{AUC}_{0-\infty}$ values and plasma concentration levels over $24 \mathrm{~h}$, compared to commercial Stuval ${ }^{\circledR}$ tablets. These data illustrate the gastroretentive capability of the microballoon formulation, as well as the importance of the microballoon small particle size in achieving high drug bioavailability, compared to the monolithic tablet formulation [99].

Tadros et al. developed lornoxicam gastroretentive composite sponges based on an interpolymer complexation (IPC) between chitosan and chondroitin sulphate (Figure 4). The drug was dissolved and dispersed in the polymer solution and lyophilisation was applied to prepare the sponges. The sponge structure was highly porous and ensured their immediate floatation in hydrochloric acid with zero lag time. Furthermore, the IPC sponge system proved to be suitable in controlling the release of lornoxicam in hydrochloric acid for more than $12 \mathrm{~h}$ [100]. Interestingly, biphasic release profiles were recorded which were interpreted as per the "sequential layer" model [101]. This concluded that the biphasic release was due to water imbibition into the matrix and drug diffusion through the formed gel layers for the first $4 \mathrm{~h}$, followed by increasing polymer erosion and drug release for up to $12 \mathrm{~h}$ of dissolution. The drug release was dependent on the chitosan:chondroitin sulphate ratio which indicated that the formulation could be altered to achieve tailored release profiles to meet individual patient needs [100].

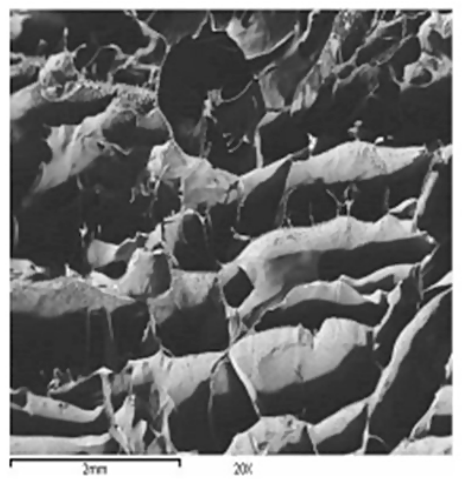

(a)

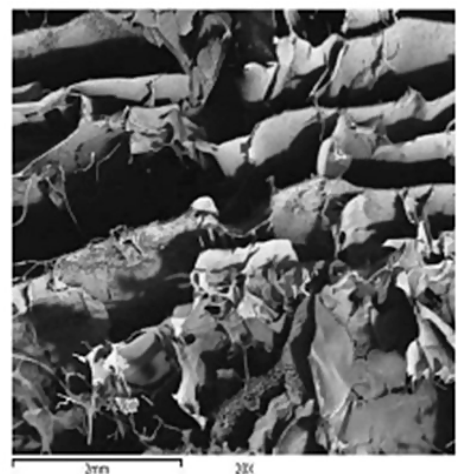

(b)

Figure 4. Scanning electron microscopy (SEM) images demonstrating the porous structure of the gastroretentive sponges before (a) and after (b) compression. The compression did not seem to damage the porous structural framework of the sponges which most likely accounted for their zero floating lag time. Reprinted from International Journal of Pharmaceutics Vol 472, Tadros and Fahmy, Controlled-release triple anti-inflammatory therapy based on novel gastroretentive sponges: Characterization and magnetic resonance imaging in healthy volunteers, Pages 27-39, Copyright 2014, with permission from Elsevier.

There are certain limitations to the application of low-density gastroretentive systems. Since they are multiple-unit systems, the release rate can be different between different doses and units. Furthermore, if system integrity is compromised, a consequent burst 
release of drug could lead to adverse effects since drug loadings tend to be higher in controlled-release formulations [92].

\subsubsection{Effervescent Floating Systems}

Effervescent systems contain a gas-forming agent and/or volatile liquids that contribute to their floatation. In a gas-generating floating system, swellable polymers are mixed with effervescent agents such as sodium bicarbonate, calcium carbonate, tartaric acid, and citric acid used alone or in combinations [10,16,102]. Upon contact of the system with gastric fluids, the gas-generating agent reacts with hydrochloric acid and $\mathrm{CO}_{2}$ gas is generated. $\mathrm{CO}_{2}$ causes the floatation of the tablet and helps maintain tablet buoyancy by getting trapped in the hydrocolloid matrix of the system. It also influences drug release properties $[1,53,103,104]$. One disadvantage of effervescent systems is the fact that, unless low-density materials are used, they show long floating lag times if the generation of gas bubbles that will promote buoyancy is not fast enough and are, therefore, under the risk of premature gastric emptying [105]. Furthermore, they are not suitable to be administered in patients with achlorhydria since the low excretion of gastric acid in these patients can lead to a higher gastric $\mathrm{pH}$, thus resulting in extended floating lag times of the effervescent systems which can be problematic for their gastric retention [13].

Effervescent floating systems can be single-layer and bilayer floating tablets and multiple-unit systems $[10,17,41]$. Single-layer tablets can be prepared by mixing the drug with the gas-generating agent(s), polymer(s) and other excipients. In bilayer tablets, different strategies can be followed. One layer may contain the drug, polymer(s), and gas-generating agent(s), whereas the other layer could constitute an immediate-release one consisting of drug and excipients without gas-forming agents and release-retarding polymer(s) [10]. The amount of a gas-generating agent, such as sodium bicarbonate, can significantly affect the total hydration volume of a tablet, along with its floatability. The higher the percentage of gas-generating agent, the greater and faster-growing hydration volumes can be, along with reduced floating lag times [17]. Additionally, the presence of sodium bicarbonate can overcome tablet floatability issues in cases where high tablet compaction forces result in low tablet porosity values that are insufficient for floatation [17]. Additionally, in other cases, one layer consists of the drug, release retardant(s) and other excipients, while the other layer is the gastroretentive layer containing the gas-generating agent(s) and hydrophilic polymer(s) [86]. Cifran ${ }^{\circledR} \mathrm{OD}$ is a ciprofloxacin commercial product that constitutes effervescent single-layer gastroretentive tablets coated with a polymer film that is responsible for tablet buoyancy.

Diós et al. assessed the effect of the relative amounts of sodium alginate, L-HPC B1 and sodium bicarbonate on different buoyancy parameters, including floating lag time, maximal floating force, maximal floating force calculated to $100 \mathrm{mg}$ tablet weight mass, time needed for maximal floating force and drug release [106]. The effect on each parameter was calculated using mathematical models and the optimised floating drug delivery compositions were successfully prepared and assessed in vivo. The optimised tablets demonstrated superior floating behaviour and biphasic release, compared to two commercially available metronidazole products. The formulation was retained for $8 \mathrm{~h}$ in rat stomach, as determined by X-ray CT [106].

Apart from hydrophilic polymers, in other cases, a hydrophobic protein, such as zein, has been used in effervescent tablets for gastric retention. Raza et al. reported the preparation of zein-based compression coated single-layer tablets. The tablet core contained zein matrix as a release retardant, while the compression coating was comprised of zein and sodium bicarbonate. The tablets showed a short floating lag time and a total floating time longer than $12 \mathrm{~h}$, along with a 12-h controlled release of captopril [104]. Increasing amounts of sodium bicarbonate accelerated drug release rate from the matrix, probably due to higher pore formation that allowed for increased penetration of the dissolution medium into the matrix. The floating mechanism was a combination of rapid formation of 
pores the size of which grew over time (confirmed via scanning electron microscopy and porosity studies) and $\mathrm{CO}_{2}$ entrapment in the swelling matrix [104].

Recently, studies have reported the use of nanofibre technology for gastric retention purposes. Nanofibres are generally produced via electrospinning and can be tuned to provide controlled release of drugs through different mechanisms [107-110]. Nanofibres can offer specific benefits as part of an effervescent GRDDS. These include their high porosity that can promote the penetration of gastric hydrochloric acid into the effervescent film within the nanofibre, as well as their ability to entrap the generated $\mathrm{CO}_{2}$ gas which, not being able to diffuse out of the system, significantly prolongs the floatation of GRDDS [111]. Furthermore, alongside their high porosity, the high surface area-to-volume ratio of nanofibres results in an intrinsically low bulk density which helps ensure their immediate buoyancy upon contact with the gastric fluids [112]. Tort et al. reported the development of self-inflating effervescent nanofibre membranes containing pramipexole as the API [113]. A mixture of Eudragit ${ }^{\circledR}$ RL and RS polymers was employed to control drug release kinetics, while the effervescent films consisted of PEO and sodium bicarbonate and were embedded into the nanofibre membranes. Due to their low bulk density, the nanofibres floated immediately in simulated gastric fluid (SGF). Furthermore, the study demonstrated that the presence of $\mathrm{CO}_{2}$ gas generated in the membrane structure seemed to be crucial for prolonged floatation of the nanofibres since the effervescent nanofibres floated longer than $72 \mathrm{~h}$, while the non-effervescent nanofibre membranes did not float effectively. In terms of in vitro drug release, the presence of Eudragit ${ }^{\circledR}$ RS ensured minimum burst release from the nanofibres. The release of pramipexole was controlled over $24 \mathrm{~h}$ and mainly occurred via drug diffusion, as demonstrated by fitting of the release data to the Korsmeyer-Peppas model [113].

Multiple-unit effervescent floating systems may consist of sustained-release cores surrounded by one or more layers. The layer(s) can contain gas-forming agents along with polymers with swelling properties $[10,41,53]$.

\subsubsection{Raft-Forming Systems}

Raft-forming system is comprised of effervescent excipient(s) and gel-forming polymers to achieve floatation and a sustained release of drugs. These systems are tablets or liquids at room temperature that can undergo gelation when in contact with gastric fluids, due to an increased temperature, or as a response to $\mathrm{pH}$ change. Therefore, their behaviour can be either temperature-dependent or characterised by cation-induced gelation. Either way, the formation of a gel that is thick enough to remain intact for hours within the stomach contents leads to their buoyancy and controlled drug release applications $[41,114,115]$. This system is mostly used to achieve localised effects. Floating rafts can act as a blockade between the oesophagus and the stomach. This property renders these formulations ideal for the management of gastric oesophageal reflux disease. Furthermore, when an antacid is incorporated into the raft-forming system in significant amounts, the system can aid in the treatment of both indigestion and heartburn via acid neutralisation in both the stomach and the oesophagus $[116,117]$. Upon contact with the gastric fluids, these systems swell and form a viscous cohesive gel layer termed a raft [10,41,118]. Raft systems are used for the delivery of antacids, such as simethicone, aluminium hydroxide and calcium carbonate. However, the mechanical strength of the raft is weak, which could result in its premature disruption by the MMC $[114,118]$. Gaviscon ${ }^{\circledR}$ is a commercial raft-forming formulation that is available as tablets or liquids. It is used to treat indigestion and heartburn. Its raft-forming mechanism is based on a combination of sodium alginate, sodium bicarbonate and calcium carbonate. Topalkan ${ }^{\circledR}$ is an antacid formulation containing aluminium and magnesium as active components, while alginic acid is the raft-forming excipient.

Fabregas et al. prepared an antacid raft-forming system that contained almagate as the active component. Sodium alginate was used as the raft-forming polymer and sodium bicarbonate and acid neutraliser as effervescent agents [119]. The presence of the effervescent agents contributed to the prolonged gastric residence of the novel system 
which therefore proved to be promising as an antacid formulation [119]. Nabarawi et al. prepared a controlled-release floating raft system that contained mebeverine as the API. A combination of hydrophilic and lipid polymers was used in the formulation and the system was characterised for its floating behaviour and in vitro drug release [120]. A viscous and cohesive gel was formed upon polymer swelling that entrapped $\mathrm{CO}_{2}$ bubbles generated by the reaction of carbonates and hydrochloric acid [9]. Drug release occurred via a Fickian diffusion mechanism. A pharmacokinetic study of the optimised raft system in Beagle dogs demonstrated that the formed raft remained intact for more than $12 \mathrm{~h}$ in the Beagle dog stomach promoting the sustained release of the antacid [120].

Wannasarit et al. reported the development of a gastroretentive raft-forming system based on Eudragit ${ }^{\circledR}$ EPO-Centella asiatica extract-solid dispersions containing the poorly soluble asiaticoside and madecassoside which have proven to be effective against gastric ulcers $[121,122]$. The solid dispersion approach proved to be able to enhance the aqueous solubility of the glycosides, while the presence of HPMC K100M in the raft ensured a sustained release of the compounds over $8 \mathrm{~h}$ with the release kinetics and mechanism being controlled by Fickian diffusion for both glycosides. Furthermore, the raft strength was higher than $7 \mathrm{~g}$ and hence could be considered strong and coherent and be able to withstand the peristaltic movements of the gastrointestinal tract [122,123].

While liquid is the most common formulation form for raft-forming systems, recently, Hanif et al. reported the development of gastroretentive raft-forming tablets containing ibandronate. Nanosized citrus pectin (NCP) was prepared and used as the raft-forming polymer in the tablets, due to its gelling, antacid and antiulcer properties [124]. When combined with calcium carbonate, NCP demonstrated the highest gel strength, due to a cross-linking pattern of the raft through the calcium ions [125]. The tablets demonstrated a rapid release of ibandronate that was completed within $20 \mathrm{~min}$, potentially due to rapid diffusion of the drug through the foam structure of the raft that was ought to the incorporation of NCP into the formulation. Furthermore, an in vivo study in albino rats demonstrated an enhanced bioavailability of ibandronate in the rats, compared to a reference formulation, potentially due to the effective penetration enhancement of PEG 400 [124].

In general, the use of floating systems comes with certain potential issues. These include the possibility that system units may stick together (for multiple-unit systems) or be obstructed in the GIT, which could cause gastric irritation. Therefore, drugs that may have an irritating effect on the gastric mucosa are not considered suitable candidates for floating systems $[10,41,59]$.

\subsection{High-Density Systems}

High-density systems have a density greater than that of gastric fluids $\left(1.004 \mathrm{~g} / \mathrm{cm}^{3}\right)$ and therefore sink to the bottom of the stomach fluids and achieve gastric retention, probably via increased resistance to the gastric contractions that is linked to their high density (Figure 5) [54]. Excipients that are commonly used to ensure a sufficiently high density of these systems include barium sulphate, zinc oxide, iron oxide, iron powder, and titanium dioxide. Usually, the dosage forms reported in the literature are high-density pellets or tablets [126,127].

Sharma et al. reported the preparation and characterisation of gastroretentive highdensity pellets containing zero-valent iron nanoparticles (ZVINPs) [127]. Barium sulphate was used as the high-density component, while Carbopol ${ }^{\circledR}$ was incorporated as the release retarding agent. The sinking time test demonstrated an immediate sinking of the optimised pellets, while they were able to retard the release of iron over $19 \mathrm{~h}$ in vitro, due to the presence of Carbopol ${ }^{\circledR}$. An in vivo study was conducted in male Wistar rats and the X-ray analysis showed that the pellets were retained in the stomach over $10 \mathrm{~h}$, while the plasma concentration of iron remained at high levels over $24 \mathrm{~h}$ with minimum fluctuations that can be attributed to the controlled release of iron from the pellets [127]. 


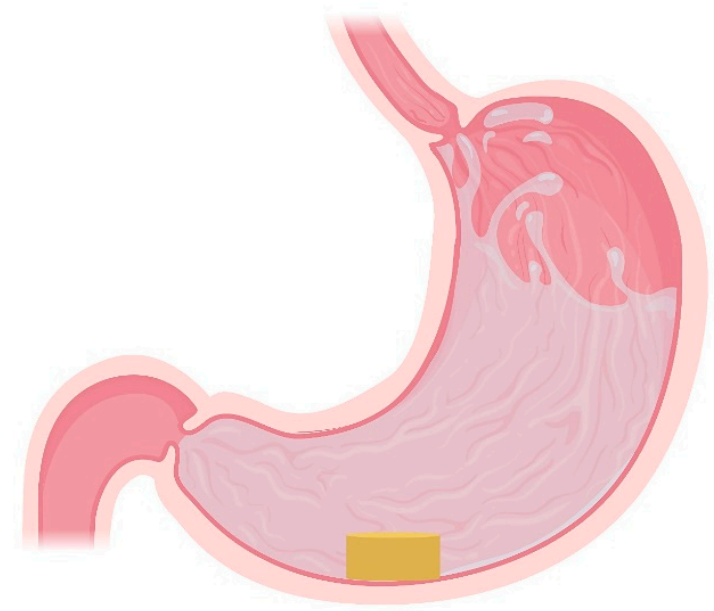

Figure 5. Schematic localisation of high-density systems in the stomach. The figure was created using BioRender (www.biorender.com) (accessed on 3 August 2021).

Desai et al. developed a novel multiparticulate pulsatile high-density tablet containing clopidogrel. The aim was to prepare tablets that would be retained in the stomach for $7-8 \mathrm{~h}$ and release the drug after a predetermined lag time [126]. Iron oxide was used as the density-increasing agent and high-density pellets were prepared using extrusion and spheronisation, followed by their compression into tablets. HPMC K4M and ethylcellulose were used as coating materials to achieve a lag time of $6 \mathrm{~h}$, followed by a burst release of clopidogrel. The in vitro release results demonstrated a rapid release of the API after a 6-h lag time. Furthermore, an in vivo X-ray study in albino rabbits demonstrated 8-h retention of the tablets in the animal stomach. Therefore, this combination of multiparticulate pulsatile and high-density gastroretentive systems demonstrated a successful contribution towards a chronotherapeutic effect of clopidogrel [126].

Even though such systems are promising in achieving long gastric residence times (GRTs), it is difficult to design high-density pellets containing high doses of drugs. Furthermore, the clinical significance of these systems is yet to be proven since only few animal studies have been carried out $[10,63]$.

\subsection{Mucoadhesive/Bioadhesive Systems}

Adhesion is the process by which two surfaces are "fixed" to one another [128]. When adhesion happens in a biological setting, it is referred to as "bioadhesion", while if it occurs on mucosal surfaces it is termed "mucoadhesion" [30]. Regarding gastric retention applications, this system can adhere to the surface of the gastric mucosa and prolong the GRT of drug compounds (Figure 6) [20,41]. In these systems, the drug is incorporated into one mucoadhesive agent or a combination of them that can be natural or synthetic hydrophilic polymer(s). Xifaxan ${ }^{\circledR}$ is a commercial bioadhesive tablet formulation containing rifaximin as an antibiotic and is used to treat traveller's diarrhoea, hepatic encephalopathy, and irritable bowel syndrome with diarrhoea (IBS-D).

Mucoadhesion is achieved through bond formation between the swelling polymer and mucous surface [31]. This is a process consisting of two steps, the contact stage and the consolidation stage [129]. Different theories supplementary to one another have been reported about the mechanism of mucoadhesion. These include the wettability theory, the electronic theory, the fracture theory, the adsorption theory and the diffusion-interlocking theory [30,130-132]. 


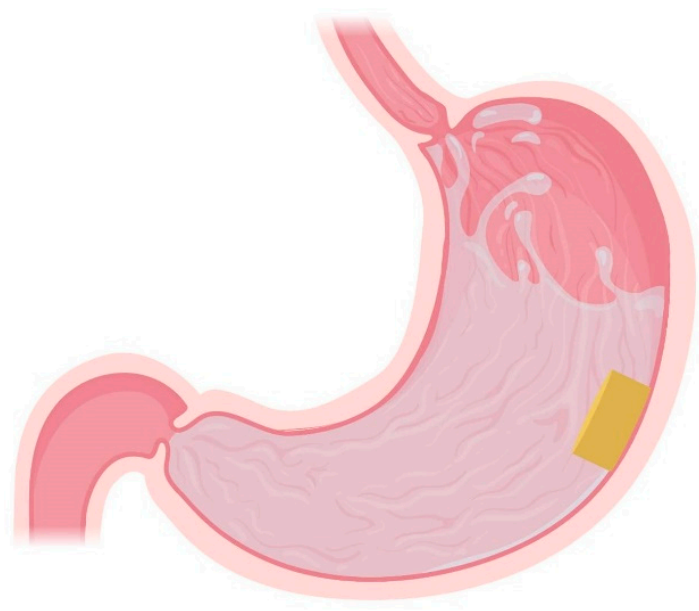

Figure 6. Localisation of mucoadhesive/bioadhesive drug delivery systems in the stomach. The figure was created using BioRender (www.biorender.com) (accessed on 3 August 2021).

The wettability theory proposes that the adhesive component of a drug delivery system penetrates surface irregularities, hardens and subsequently anchors itself to the surface [30]. This theory applies to liquid or low-viscosity mucoadhesive systems and the critical attribute that is used to measure their adhesion performance is the wettability and spreadability of the system across the biological substrate. These parameters are dependent on the contact angle of the two surfaces. Lower water:polymer contact angles will facilitate the hydration of these systems, thus promoting the interaction between the polymer and the mucosal surface chains [133]. Additionally, mucoadhesive systems with similar structure and functional groups to the mucus layer may show increased miscibility which, in turn, leads to a greater degree of polymer spreadability across the mucosal surface [30].

The electronic theory postulates that adhesion can take place via electron transfer between the mucoadhesive system and the mucus due to differences in their electronic structures. This electron transfer generates a double layer of electrical charges at the mucoadhesive system:mucus interface that leads to the formation of attractive forces [130]. However, this theory is considered controversial since electrostatic forces are not just considered a result of high joint strength, but rather a predominant cause of adhesion $[30,128]$.

According to the fracture theory, the adhesion strength between two surfaces is related to the force that needs to be applied to separate the two surfaces. In terms of mucoadhesion, this theory relates the force required to detach the polymer system from the mucus to the strength of the adhesive bond. The fracture work seems to be dependent on the polymer chain length and the degree of cross-linking in the polymer network. More specifically, an increase in the former or reduction in the latter increases the work of fracture [134].

The adsorption theory suggests that adhesion could be the result of different surface interactions between the adhesive polymer and the mucus, termed primary and secondary bonding. Primary bonding includes ionic, covalent and metallic bonds which are generally strong and persistent and are, therefore, not desirable $[28,30,128,135]$. Secondary bonding includes mainly van der Waals interactions, hydrophobic and hydrogen bonds $[28,135]$. Even though these interactions require less energy to break, they are considered the most prevalent in terms of surface interactions in mucoadhesion processes, probably because they are semi-permanent bonds $[128,131,134]$.

The diffusion-interlocking theory refers to a time-dependent diffusion of the adhesive polymer chains into the glycoprotein network of the mucus. This is a two-way process since the polymer networks diffuse into one another with the penetration rate depending on the diffusion coefficients of both inter-penetrating polymers. The factors that most significantly affect this polymer interaction are molecular weight, cross-linking density, chain mobility and expansion capacity of each of the polymer networks [132,136-138]. Additionally, temperature is an environmental factor that can affect this process via an 
effect on the friction coefficients of the polymers [139]. It is suggested that, for a successful interpenetration and chain entanglement at a molecular level to occur, a minimum chain length of $100,000 \mathrm{Da}$ is required $[30,140,141]$. The effectiveness of adhesive polymer chains to interact, diffuse, interpenetrate and achieve inter-locking with the polymer chains of the surface mucus increases with their length. Furthermore, increased cross-linking density results in reduced polymer chain mobility, thus leading to a decline in interpenetration [140]. In addition to the above, the miscibility of the two polymer systems with one another is very important in achieving effective interpenetration. Therefore, maximum diffusion and adhesion can be achieved when the solubility values of the adhesive and mucus polymer networks are similar [135].

Many different mucoadhesive dosage forms have been reported in the literature, including beads, microspheres, films, capsules and tablets [28]. Polymers such as chitosan, sodium alginate, HPMC, polyethylene glycol and polyacrylic acid have mucoadhesive properties that render them suitable for use in these systems $[9,41]$. These polymers bind to the mucosal surfaces and, thus, maintain the drug in continuous contact with the mucus and increase the residence time of the drug at the application site. These polymers should be inert, non-irritating to the mucosa, non-toxic, adhering to the mucosal surface and site-specific [10].

Chitosan hydrogels have been used extensively in gastroretentive drug delivery system applications. Chitosan can form gels with improved mechanical strength through chemical cross-linking using glutaraldehyde, glyoxal or other substances as cross-linkers, or through physical cross-linking as ionically cross-linked chitosan gels with multi-valent phosphates or as polyionic complexes of positively charged chitosan with a negatively charged polymer, such as alginate or polylactic acid. Chitosan-based hydrogels have been used for mucoadhesive and other gastroretentive, as well as controlled-release, applications [47,142-153].

Poly(acrylic acid) (PAAc) and its derivatives have been reported as excellent mucoadhesive agents [48]. Sarkar et al. developed metformin mucoadhesive tablets where a graft-copolymer of PAAc with gellan gum (GG) was used as the adhesive agent. GG was used as the main polymeric backbone and PAAc was grafted onto it [19]. After the synthesis was completed, PAAc-g-GG-based tablets were prepared, alongside GG-, HPMC K15M- and Carbopol ${ }^{\circledR}$-based ones. The viscosity of polymer solutions formed by the PAAc-g-GG graft-copolymers with the maximum amount of grafting was found to be the highest which was expected since branched polymers tend to have higher viscosity values than linear chain polymers. In terms of in vitro drug release, the tablets containing copolymers with a high degree of grafting demonstrated a sustained release of metformin over $10 \mathrm{~h}$, likely due to their comparatively denser network leading to slower water uptake and network relaxation. The drug release from most of the formulations followed Higuchi and Korsmeyer-Peppas kinetics, alongside a Fickian-diffusion-based mechanism of drug release. Finally, regarding mucoadhesion, GG-only tablets showed no such capability, while the PAAc-g-GG tablets demonstrated a strong mucoadhesion on goat stomach mucosa ex vivo, based on their long mucoadhesion time and high adhesion strength. This is probably due to numerous - $\mathrm{COOH}$ groups that can form multiple hydrogen bonds with the mucus molecules under an acidic environment that favours interaction of these groups with the mucin rather than the surrounding water. Therefore, PAAc-g-GG-based tablets are promising in improving the oral bioavailability of drugs with a narrow absorption window, such as metformin [19].

Nanoparticles are in general known to suffer from a rapid passage through the stomach and intestine, and thus being unable to release drugs in a controlled manner and to an acceptable extent [20]. This limits their oral applications. To address this challenge, Sarparanta et al. developed thermally hydrocarbonised porous silicon (THCPSi) nanoparticles [20]. Porous silicon was used since it is known for its biocompatibility and biodegradability, as well as variable particle size, pore size and degree of porosity $[154,155]$. The nanoparticles were coated with hydrophobin class II which ensured the efficient dis- 
persal of the nanoparticles in aqueous media with minimal aggregation. During an in vitro study on human gastric adenocarcinoma (AGS) cells, the nanoparticles demonstrated a gradual adhesion to the cells over time with $35 \%$ of the nanoparticles being retained for at least $4 \mathrm{~h}$ on the cells. However, it took 30-60 min for the nanoparticles to be attached to the cells with the mucoadhesion achieved probably via hydrophobic and electrostatic interactions. Nevertheless, an in vivo biodistribution study in rats demonstrated that the nanoparticles were able to be retained in the rat stomach for $3 \mathrm{~h}$, prior to their emptying from the stomach towards the duodenum, where the hydrophobin class II coating would be expected to be shed, due to the presence of surfactants [20].

The use of mucoadhesive systems comes with certain limitations. Site targeting can be challenging, due to differences in the composition of the mucus across the mucosal membrane. Furthermore, the constant turnover of the mucus, along with high stomach hydration, can contribute to a reduced bioadhesion of the systems. Finally, there is a risk of adhesion of the system to the oesophagus which could result in collateral lesions $[9,56]$.

\subsection{Expandable Systems}

Expandable drug delivery systems are designed to grow in size or reconfigure their geometry within the stomach to prevent passage through the pyloric sphincter and have a longer GRT [15]. These systems need to have a small size for easy oral intake, expand in the stomach and attain dimensions larger than the diameter of the pyloric sphincter and have their size reduced after drug release is completed, for them to be evacuated from the stomach $[5,9,15]$. Due to their ability to block the pyloric sphincter, these systems are also referred to as "plug-type" systems. It has been suggested that these systems should expand to a size greater than $15-16 \mathrm{~mm}$ in the fasted state and greater than $12-13 \mathrm{~mm}$ in the fed state to ensure successful gastric retention, based on the resting orifice of the pyloric sphincter $(12.8 \pm 7 \mathrm{~mm})[156,157]$. Furthermore, a sufficiently high tablet wet strength is an additional requirement that will ensure the protection of gastroretentive tablets from premature rupture and emptying under the effect of the housekeeper waves [158]. The expansion takes place through swelling and/or unfolding which allows for volume and shape modification, respectively $[15,159]$. Accordion Pill ${ }^{\circledR}$ Levodopa/Carbidopa is a commercial expandable capsule formulation containing carbidopa and levodopa as active components and is used to treat Parkinson's disease. It achieves gastric retention via an unfolding mechanism through the presence of folded multilayer polymeric films. Additionally, Acuform ${ }^{\circledR}$ and Geomatrix ${ }^{\circledR}$ are two expandable system technologies that have been used in commercial gastroretentive formulations, such as Requip ${ }^{\circledR}$ XL (ropinirole), Glumetza ${ }^{\circledR}$ (metformin), Nucynta ${ }^{\circledR}$ ER (tapentadol), Gralise ${ }^{\circledR}$ (gabapentin) and Janumet ${ }^{\circledR}$ XR (Sitagliptin and metformin).

Hydrophilic polymers, such as HPMC, PEO and Carbopol ${ }^{\circledR}$, are usually utilised in the swelling expandable systems due to their ability to absorb water and increase the system volume by swelling. Likewise, in unfolding systems, the drug and polymer can be in a folded/compressed state inside a gelatin capsule. When the capsule comes in to contact with the gastric fluids, it dissolves, and the mechanically preferred expanded configuration is released. In these systems, the critical attributes that need to be considered include the molecular weight, viscosity, swelling or expanding properties and biodegradability of the polymer chosen to maintain gastric retention and sustained release of the drug $[9,160]$.

Rimawi et al. developed an expandable matrix system in the form of a layer that contained gabapentin as the API. Gelatin was used as a swellable hydrophilic polymer which increased in size upon contact with the body fluids, as well as a plasticizer (Poloxamer 407 ) that increased the flexibility of the layer, and hydrophobic polymers (Eudragit ${ }^{\circledR}$ L100, L100-55 and S100) as release retarding agents [161]. The system was able to unfold and expand within $15 \mathrm{~min}$ to a diameter larger than $20 \mathrm{~mm}$ after contact with hydrochloric acid dissolution medium which could potentially prevent a premature evacuation of the system from the stomach (Figure 7). The unfolding mechanism involved a specific combination of citric acid and sodium bicarbonate trapped in-between the folded layer parts. When 
activated, it generated carbon dioxide gas that helped push the folded parts away from each other. Furthermore, the release of gabapentin was retarded for longer than $6 \mathrm{~h}$ and followed zero-order kinetics [161].

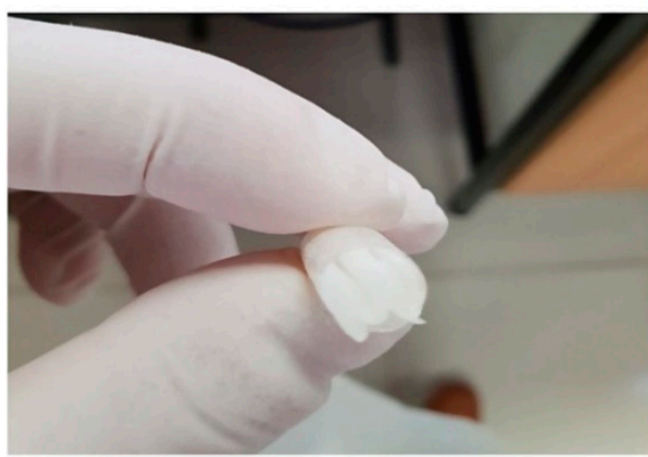

(a)

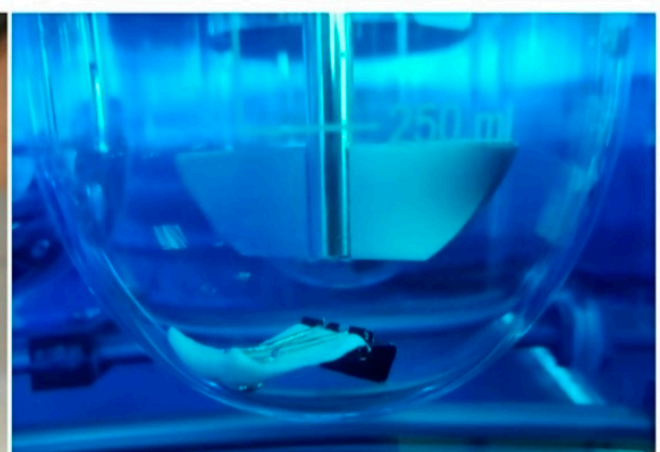

(b)

Figure 7. Transition of the gabapentin-loaded polymer layer from the folded (a) to the expanded (b) state during in vitro release testing [161]. The present figure combines Figures 11 and 12 from the original research paper [161].

Xanthan gum has shown promising properties as a swelling and expanding agent either used solely or in combination with other materials, such as guar gum [162]. In a study, xanthan gum was compared against sodium alginate, gellan gum and pectin in the development of levofloxacin gastroretentive tablets, regarding the polymer ability to swell and retard drug release. Xanthan gum was able to swell rapidly and maintain a thick gel over $24 \mathrm{~h}$, whilst releasing levofloxacin over $8 \mathrm{~h}$. The release of levofloxacin from the optimised tablets followed Weibull kinetics with a non-Fickian diffusion mechanism [156].

Bellinger et al. developed an ultra-long-acting ivermectin gastroretentive expandable system. The system was a stellate dosage form consisting of six arms joined at a central core made of an elastomeric material. The arms consisted of solid dispersions of the drug based on a linear polycaprolactone (PCL) polymer and Pluronic ${ }^{\circledR}$ P407. The base of the system that was responsible for the unfolding mechanism consisted of a PCL-based polyurethane (PU) thermoset elastomer. This material can undergo a high degree of strain without tearing, expand rapidly within 5 to 30 min after removal from the capsule and remain deformed within the capsule without risk of plastic deformation [163]. PCL is a hydrophobic polymer that swells minimally in water and is stable in strongly acidic conditions. The dosage form was able to control the release of ivermectin over longer than 2 weeks both in vitro and in vivo after oral administration in pigs. Drug release occurred through polymeric matrix erosion. Furthermore, enteric linkers present in different parts of the system ensured its dissociation into small pieces to ensure an eventual safe passage through the small intestine. However, due to the characteristics of the polymer matrices that are necessary to maintain a long gastric residence of the system, its application is limited only to small doses of drugs [163]. Although the efficacy of the system needs to be confirmed in humans, its application as an ultra-long-acting gastroretentive form is promising and advanced for oral drug delivery applications for the treatment of a broad range of clinical conditions [164].

Kirtane et al. employed the same concept (Figure 8) as Bellinger et al. for a onceweekly oral administration of a combination of the antiretroviral drugs-dolutegravir, cabotegravir and rilpivirine [165]. Here, the researchers created a formulation consisting of a combination of thermoplastic urethanes Elastollan ${ }^{\circledR} 1185$ and Elastollan ${ }^{\circledR}$ R6000 as the solid dispersion matrix for the drugs. This combination provided improved mechanical properties, regarding their value for maximum stress and resistance towards repetitive stomach bending forces [165]. The release of all the drugs was sustained over 7 days both in vitro and in vivo after oral administration in pigs, with their plasma concentration remaining approximately within steady-state levels over the 7-day period. By employing 
mathematical modelling methods to evaluate the impact of the delivery system on patient outcomes and epidemiological trends, the authors estimated a significant potential for the improvement of patient adherence to HIV treatments, thus improving patient health, whilst significantly reducing the number of new HIV infections [165]. However, the same limitations apply to this system, regarding the low doses of drugs that can be incorporated into these systems, as well as the requirements for stability of drugs in acidic $\mathrm{pH}$, elevated temperatures and high humidity $[163,165]$. Based on the research results, the company that contributed to the development of this technology, Lyndra ${ }^{\circledR}$ Therapeutics, announced a Notice of Allowance obtained from the U.S. Patent and Trademark Office (USPTO) for this technology under the name "Long-acting Pill" (US20170266112A1 patent). A once-a-week risperidone treatment for schizophrenia showed promising data in phase II clinical trials [166], while other drugs treating different clinical conditions have been formulated into the Long-acting Pill and are bound for and/or undergoing phase I clinical trials $[167,168]$.

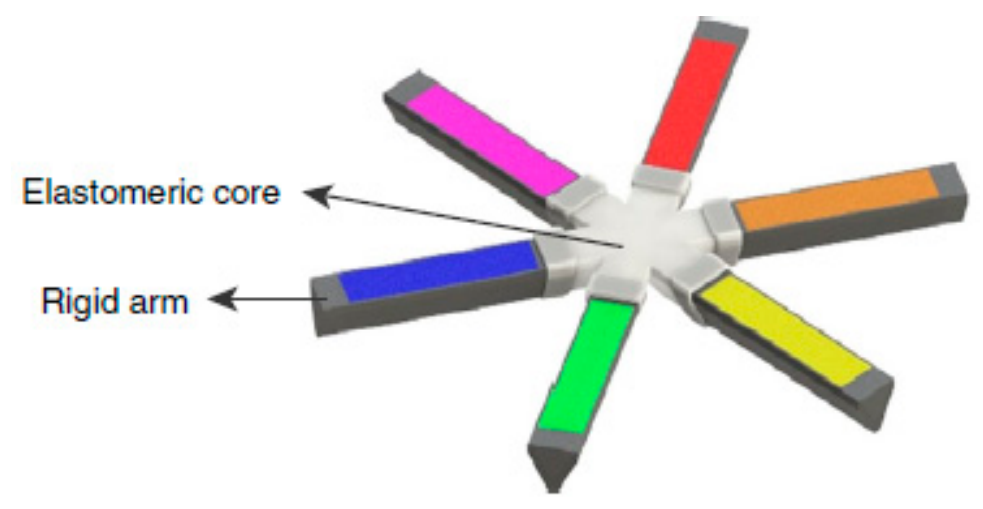

Figure 8. Design of the "Long-acting Pill" technology in its expanded form. The dosage form consists of a water-insoluble elastomeric core and six drug-loaded polymeric arms. Reprinted from Nature Communications Vol 9, Kirtane et al., Development of an oral once-weekly drug delivery system for HIV antiretroviral therapy, Pages 1-13, Copyright 2017, published under a Creative Commons Attribution 4.0 International License (http:/ / creativecommons.org/licenses/by/4.0/, accessed on 2 August 2021) (the "License"). No changes were made to the original figure presented as Figure 1a in the original research paper.

The applications of expandable systems come with a few limitations. There are difficulties in storing easily hydrolysable and biodegradable polymers, while manufacturing can be challenging, alongside a potential lack of cost-effectiveness. Furthermore, there can be challenges in maintaining the structural integrity of the systems in the stomach. Finally, the application of this type of system may cause adverse effects such as bowel obstruction, intestinal adhesion, and gastropathy $[2,9,15]$.

\subsection{Superporous Hydrogel Systems}

These systems have gained high popularity as controlled-release formulations, due to their high mechanical strength and elastic properties [33]. Superporous hydrogels are highly cross-linked polymers that can absorb significant amounts of aqueous fluids and swell within relatively short periods to form a stable gel $[169,170]$. Such systems have a pore size greater than $100 \mu \mathrm{m}$. This enables them to rapidly absorb water by capillary wetting and swell to an equilibrium size in a short time (Figure 9) [5,169]. While the conventional hydrogel system swelling is a slow process and can result in premature evacuation from the stomach, superporous hydrogels can swell up to 100 times or more and can gain enough mechanical strength to resist pressure from gastric contractions, thereby increasing the GRT. In these systems, highly swellable polymers, such as sodium croscarmellose and sodium alginate are used $[9,10,32]$. However, such polymers have swelling behaviour that depends sensitively on $\mathrm{pH}$ changes, and unintended reversal or slowing of polymer swelling can 
result in poor mechanical strength of the system structure and its premature evacuation from the stomach $[9,32]$.

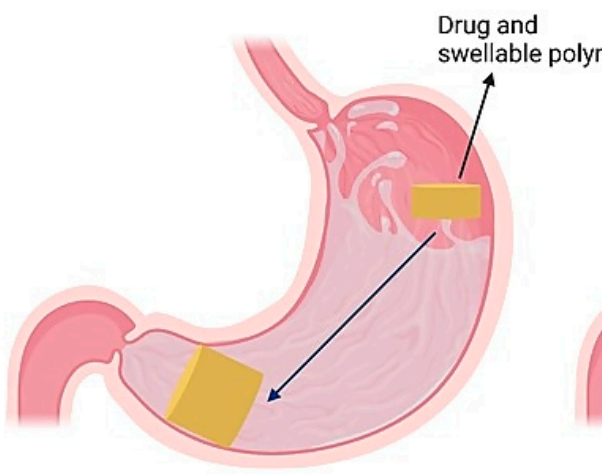

(a)

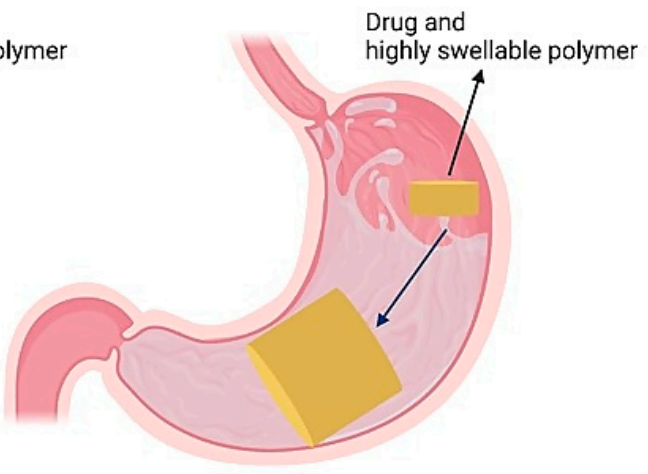

(b)

Figure 9. Intragastric behaviour of (a) expandable and (b) superporous hydrogel systems. The figure was created using BioRender (www.biorender.com) (accessed on 3 August 2021).

Three different generations of superporous hydrogels have been reported. The firstgeneration superporous hydrogel systems consisted of one cross-linked polymer [169,171]. Their mechanical strength can be enhanced by the addition of other cross-linked hydrophilic polymers into the primary polymeric network which leads to the formation of so-called second-generation superporous hydrogels (superporous hydrogel composite, SPHC). This can enhance the cross-linking density of the hydrogels without rendering them too brittle [169,172]. Finally, Omidian et al. reported the development of third-generation hydrogels which were formed through the creation of a novel interpenetrating polymer network (IPN), where sodium alginate was added in the solution of a monomer (acrylamide), a cross-linker (bisacrylamide) and the other ingredients, followed by polymerisation. The polymerised superporous hydrogel was further treated with calcium chloride to promote the metal complexation of the alginate portion of the IPN. The IPN of polyacrylamide and sodium alginate was able to swell rapidly and form a gel that was mechanically strong, highly elastic and resistant to various types of forces [172].

Bhalla et al. also reported the preparation of three different generations of superporous hydrogels containing ranitidine. Instead of sodium alginate, chitosan was used as the additional cross-linked hydrophilic polymer that was added in the primary polyacrylamide network [32]. All of these hydrogels had a density lower than $1 \mathrm{~g} / \mathrm{cm}^{3}$ which enabled their floatation in hydrochloric acid. The incorporation of chitosan in the primary polymeric network (polyacrylamide) enhanced the mechanical stability of the SPHC system, enabling it to withstand a compression force of 3-4 N, while the superporous hydrogel interpenetrating network (SPHIPN) system was elastic enough not to fracture under a 10 $\mathrm{N}$ compression force. Drug release from the SPHIPN formulations was characterised by an initial burst release which could be attributed to the API on the surface of the network, followed by sustained release over $24 \mathrm{~h}$. The incorporation of HPMC further sustained the release of the drug. The drug release followed Higuchi kinetics and mainly occurred via diffusion through the polymer matrix [32].

There are some disadvantages to the use of superporous hydrogels for gastric retention purposes. Since ionic polymers are used to a significant extent in the development of these systems, their swelling behaviour can be heavily dependent on gastric $\mathrm{pH}$ and, thus, reversible with any $\mathrm{pH}$ changes. Furthermore, sometimes they may show poor mechanical strength which can be an issue towards achieving effective gastric retention $[10,18]$.

\subsection{Osmotic Systems}

Osmotic pump technology has been widely used in oral drug delivery. Its applications come with significant advantages. These include zero-order release that is indepen- 
dent of media $\mathrm{pH}$, osmolality and food effects. Additionally, they usually provide good in vitro/in vivo correlations and a constant drug plasma concentration for the duration of the controlled drug release $[173,174]$. However, for drugs with a narrow absorption window or drugs absorbed or acting primarily in the upper part of the GIT, the residence of the osmotic system in that area may not be long enough to ensure complete drug release, thus diminishing their bioavailability and therapeutic efficacy $[175,176]$. Hence, a combination of the osmotic pump technology with a gastroretentive strategy can ensure a prolonged gastric residence time that will allow for a desirable absorption and/or pharmacological action of different drugs. $\mathrm{Coreg}^{\circledR} \mathrm{CR}$ is a commercial gastroretentive osmotic capsule formulation of carvedilol used to treat high blood pressure and heart failure.

Guan et al. prepared a gastroretentive osmotic capsule formulation with asymmetric membranes containing famotidine as the API [177]. PEO polymers of different molecular weights were tested as suspending and floating agents, $\mathrm{NaCl}$ was used as the osmotic agent and cellulose acetate was employed as the coating membrane. Orifices were drilled on either side of the capsule. The results showed that, with regard to floatation, all capsules floated immediately; however, the molecular weight of PEO had a negative effect on the total floating time [177]. The true density of PEO increases with increasing molecular weight [178]. Therefore, this negative effect on total floating time could be due to the fact that at an earlier timepoint the true density of the system was higher than that of the PEO solution formed from the swelling of the polymer in the medium. As a result of the above, due to its low molecular weight and subsequent long floating time of the systems loaded with it, PEO WSR N-80 was selected as the suspending and floating agent. The optimised formulation was selected based on a central composite design and gave a 12-h floatation and drug release in vitro that followed zero-order kinetics. Finally, a pharmacokinetic study in Beagle dogs demonstrated a sustained release of famotidine, alongside a superior bioavailability, compared to marketed famotidine tablets [177].

Desai et al. employed Quality by Design $(\mathrm{QbD})$ tools to prepare a gastroretentive osmotic system (GROS) tablet formulation containing clopidogrel bisulphate [179]. The formulation consisted of the core tablet which contained $\mathrm{NaCl}$, sodium carboxymethylcellulose, polyvinylpyrrolidone (PVP) and sodium lauryl sulphate (SLS), a cellulose acetate:PEG 4000 coating and the gastroretentive compression coating which contained HPMC K4M, sodium bicarbonate and talc. The optimised tablets conformed to the Quality Target Product Profile (QTPP) specifications as they demonstrated a 12-h zero-order release of up to $90 \%$ of the drug, with a negligible floating lag time and a total floating time longer than $12 \mathrm{~h}$. Therefore, the optimised formulation proved to be promising as a gastroretentive osmotic pump delivery system and $\mathrm{QbD}$ showed the robust results that can be delivered through its application in the formulation development process [179].

Neumann et al. developed and characterised a novel expandable osmotic system containing furosemide as the API [180]. This system consisted of two main parts. The first was a shield-shaped core oral tablet with the drug release osmotically controlled surrounded by a semi-permeable coating. The tablet was introduced into the second part consisting of swellable polymers, namely HPMC K100M and PEO (POLYOX ${ }^{\circledR}$ WSR-303). The principle of this novel system was to combine the robust release behaviour of an osmotic system with the gastroretentive expandable capabilities of swelling hydrophilic polymers. The system was characterised for its swelling, gastroretentive (using a new mechanical antrum model developed by the group [181]) and in vitro release properties, followed by a clinical trial in healthy human subjects. The results demonstrated that the swelling of the system was $\mathrm{pH}$-dependent, while its gastric retention capability could be compromised in reduced media volumes. Both compendial and non-compendial dissolution tests demonstrated a $\mathrm{pH}$-independent, pressure-resistant release of furosemide from the system, however the swellable part was destroyed during the dissolution stress test experiments which could impede the gastric retention of the system in vivo. The clinical trial illustrated an effective gastric retention of the system during fed state where the gastric transit time was significantly longer than under fasted conditions. The AUC values recorded dur- 
ing fed state were 10 times higher than the respective values after fasted intake of the system. Therefore, this study demonstrated not only the potential of this novel system for gastroretentive controlled-release applications, but also the value of using biorelevant test methods alongside conventional methods during the development of gastroretentive formulations [180].

Apart from floating and expandable osmotic systems, high-density systems coupled with osmotic technology have been reported. Guan et al. developed a high-density osmotic pump tablet using pharmaceutical iron as a density-increasing, as well as gas-forming, agent. $\mathrm{NaCl}$ was the osmotic agent and PEO assumed the roles of suspending agent and release retardant [173]. The swelling of $\mathrm{PEO}$ and the hydrogen gas generation resulting from the reaction of pharmaceutical iron with hydrochloric acid were the driving forces for a complete drug release that was controlled over $12 \mathrm{~h}$ and followed zero-order kinetics. Furthermore, a gamma scintigraphy study in Beagle dogs demonstrated that the optimised tablets were retained in the animal stomach for $7 \mathrm{~h}$, thus rendering the tablets promising for future applications [173].

\subsection{Ion-Exchange Resin Systems}

Ion-exchange resins are water-insoluble, ionic polymer materials containing two principal parts: a structural portion consisting of a water-insoluble polymer matrix and a functional portion, which is the ion-active group. The ionic groups can be either positively or negatively charged and, therefore, the resins can be either cation- or anion-exchange [182]. Based on the affinity of the ionic groups for soluble counter-ions, the ionic resins are further classified into strong and weak exchangers [183]. Sulphonic acid functional groups tend to be the most common for the strong cation exchangers, while carboxylic acid functional groups are usually present in the weak cation exchangers. For strong anion exchangers, their surface usually contains quaternary ammonium groups, while tertiary amine groups are the most common for the weak anion exchangers [182].

The drugs can be loaded into the ion-exchange resins via two methods, the batch method and the column method [184,185]. During the batch method, a certain amount of resin is immersed into a drug solution and mixing is conducted until equilibrium is reached, while in the column method, a saturated drug solution is passed through a resin-packed column until the effluent concentration and eluent concentration reach an equilibrium [186,187]. Many different factors affect the efficiency and rate of drug loading, including molecular weight and charge intensity of the drug and resin, particle size and cross-linking degree of the resin, as well as nature of the solvent used for the drug solution and mixing conditions. Large drug particle size and a high degree of cross-linking result in slower rates of drug loading, while smaller resin particle size increases the surface area of interaction between the drug and resin, thus potentially accelerating drug loading [186].

Umamaheshwari et al. developed an effervescent gastroretentive cholestyraminebased microcapsule formulation using acetohydroxamic acid as the API [188]. Sodium bicarbonate was bound onto the resin, followed by incorporation of the API, up to a level where the floating of the system was not impeded. After their preparation, the microcapsules were coated with cellulose acetate butyrate (CAB). Drug release from this system was a two-step process, including drug displacement and drug diffusion. The rate of drug release depended on the thickness of the $C A B$ coating and the dissolution medium. Increasing CAB:drug-resin complex ratios led to lower release rates because the increased coating thickness resulted in a longer diffusional path of the drug molecules displaced from the surface of the resin. The drug release from the system was faster in SGF pH 1.2 than phosphate $\mathrm{pH}$ 7.4. This can be attributed to the higher affinity of the cholestyramine functional groups towards chloride ions than phosphate ions, due to the initial treatment process of the resin, as well as the size of the ions. Phosphate ions are bulkier than chloride ions which slows their diffusion through the resin particles. The buoyancy lag time of the microcapsules was 2-5 min and they floated for $12 \mathrm{~h}$ with a

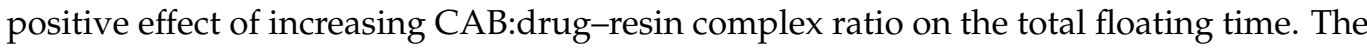


floatation of the system in SGF was achieved through the entrapment of $\mathrm{CO}_{2}$ gas into the $\mathrm{CAB}$ coating which was generated from the reaction between sodium bicarbonate and hydrochloric acid. The drug release was controlled over more than $8 \mathrm{~h}$. Finally, apart from the floating properties of the microcapsules, their bioadhesion capability was confirmed in a rat stomach. This combination of floating and bioadhesion properties rendered the system promising in achieving robust gastric retention that can help treat Helicobacter pylori effectively [188].

The application of ion-exchange systems comes with certain limitations. There are safety issues concerning their ingestion. Furthermore, the amount of resin bound with the drug(s) may be difficult to estimate [10]. Finally, the applications of ion-exchange resins as a controlled-release platform are restricted to drugs with groups that can be charged [186].

\subsection{Magnetic Systems}

In magnetic systems, the distinct feature in the dosage form is a small amount of internal magnet, apart from API and excipients. An extracorporeal magnet is placed over the stomach to control the position of the dosage form (Figure 10) [10]. The gastric retention behaviour of the magnetic systems can be affected by the position and magnetic intensity of the extracorporeal magnet [58].

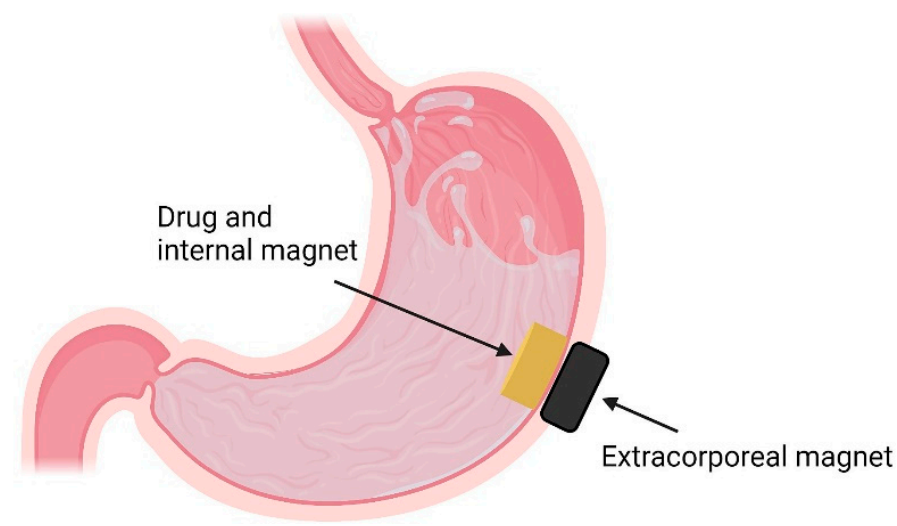

Figure 10. Application of magnetic drug delivery systems for gastric retention purposes. The figure was prepared using BioRender (www.biorender.com) (accessed on 3 August 2021).

In the literature, it has been reported that the GRT and bioavailability of drugs are improved using magnetic tablets [34,189]. Gröning et al. tested the gastric retention capability of acyclovir magnetic depot tablets in human volunteers with and without the application of an external magnetic field. The tablets remained in the stomach for a prolonged period in the presence of the extracorporeal magnet and the area under the concentration curve values were significantly increased [35].

Zhou et al. developed gastroretentive adhesive tablets that contained superparamagnetic iron oxide nanoparticles (SPIONPs) which generated microbubbles in situ that induced cavitation upon application of ultrasound energy from an external machine [36]. Iron oxide nanoparticles have been reported as a promising nanomedicine in the past, due to their biocompatibility, intrinsic superparamagnetic properties and biodegradability $[190,191]$. The tablets were prepared by mixing sodium bicarbonate (foaming agent) with HPMC K4M and/or Carbomer 934P which, being swellable hydrophilic polymers, were responsible for the tablet adhesion and/or controlled release of microbubbles from the system. The study results showed that the presence of the foaming agent was crucial in ensuring a stable generation of $\mathrm{CO}_{2}$ bubbles in situ in an acidic environment, while the presence of an adhesive polymer was necessary for preventing a premature disintegration of the tablets. Furthermore, the combination of HPMC K4M and Carbomer 934P at a ratio of 1:1 was ideal as the adhesive component of the delivery system since, under the application of ultrasound energy, a controlled release of bubbles over $12 \mathrm{~h}$ was demonstrated, while 
the tablets were not completely dissolved. Additionally, increasing the ultrasound intensity applied seemed to significantly increase the release rate of the SPIONPs from the system in vitro, whilst accelerating the dissolution of the tablets. Finally, an ex vivo study using pig stomach tissue demonstrated an increased penetration and dispersion of the released nanoparticles into the mucosal and muscle layers under ultrasound application, compared to when ultrasound energy was absent. This demonstrated that the release and absorption of nanoparticles can be regulated through the application of external acoustic energy. Furthermore, it was suggested that application of an external magnet could further aid the localisation of the tablets in the stomach and further ensure effective gastric retention [36]. This application could be a promising step towards the development of gastroretentive magnetic nanoparticle-based formulations that will help achieve an effective local and systemic administration of drugs. However, the use of specialised external equipment, such as ultrasound devices and/or external magnets, is essential for desired drug release and gastric retention behaviours of such formulations.

A major challenge associated with the application of magnetic systems is the fact that specific positioning of the magnet can be challenging and could also lead to low patient adherence [58]. Therefore, future research studies on these gastroretentive systems need to focus on their clinical significance.

\subsection{Combinatory Approaches}

Apart from the abovementioned standalone gastroretentive technologies, combinations have been reported. Combinatory approaches can help tackle the disadvantages of each of the different technologies combined. Additionally, they can help minimise the variability of GRT and may be less affected by the physiological conditions of the stomach, such as those during fasted and fed state, thus ensuring robust gastric retention [10]. These combinations could be floating and expandable systems, mucoadhesive and expandable systems and floating and mucoadhesive systems. The first two combinations have indicated to have higher safety and efficacy for clinical applications [192].

\subsubsection{Floating and Expandable Systems}

This category includes GRDDS that are designed to float and expand or swell. These formulations need to possess four characteristics. To begin with, the initial dosage form must be small enough for swallowing. Once the dosage form reaches the stomach after co-administration with water, it should float and remain buoyant to avoid a premature evacuation from the stomach. Then, as it comes in contact with the gastric fluids, it should rapidly expand to a certain size that will prevent its passage through the pyloric sphincter. Finally, when there is no need for the formulation to be gastroretentive anymore, it can be reduced to a size that will allow gastric emptying [87,193,194]. Highly swellable polymers, such as HPMC K4M, K15M and K100M, PEO and chitosan can be used to achieve a desirable swelling index for the formulations $[2,105,195]$.

Chen et al. developed losartan GRDDS tablets containing a mixture of hydroxyethylcellulose and chitosan as swelling polymers, while sodium bicarbonate was used as a gas-generating agent [2]. A decrease in the viscosity of chitosan resulted in better swelling behaviour of the formulation, probably due to more rapid penetration of the medium in the tablet which promoted the swelling of hydroxyethylcellulose. Additionally, sodium bicarbonate seemed to have a negative effect on the swelling of chitosan, probably due to the neutralisation of the medium $\mathrm{pH}$ around the tablets which potentially resulted in hindrance of the polymer swelling. Therefore, the optimum polymer:sodium bicarbonate ratio was crucial in obtaining the preferred behaviour of GRDDS. The optimised tablets contained an equivalent ratio of the two polymers and were able to control the release of losartan over $16 \mathrm{~h}$ in vitro, whilst demonstrating a good swelling and floating behaviour of the system The drug release potentially followed the Case II diffusion model kinetics, meaning that it followed the rate of swelling of the hydrogel matrix which led to a constant release [2]. 
Hwang et al. developed swellable, highly porous bilayer tablets containing ranitidine [105]. The gastroretentive layer consisted of a swellable polymer and had a highly porous structure, due to the removal of volatile materials during a sublimation process step. Different hydrophilic polymers and sublimating agents were tested for their properties to choose the most suitable materials for the gastroretentive layer. Eventually, PEO was selected as the optimal polymer, due to its persistent swelling over $12 \mathrm{~h}$ and its ability to ensure a high tablet wet strength, as well as maintaining a high tablet tensile strength even after sublimation. Between camphor and menthol, camphor was chosen as the optimal sublimating agent, due to its significantly higher sublimation rate and its much smaller negative effect on tablet tensile strength, compared to menthol. Additionally, HPMC K4M was incorporated into the formulation to retard the release of ranitidine. X-ray microcomputed tomography of the tablets demonstrated a highly porous internal tablet structure where the pores were evenly distributed (Figure 11), thus ensuring a sufficiently low density for a robust floatation and suggesting that buoyancy could be maintained even after a slight surface erosion of the gastroretentive layer in vitro or in vivo. The tablets were able to retard the release of ranitidine over $12 \mathrm{~h}$ in vitro with the release significantly affected by the amount of HPMC K4M, the percolation threshold of which was determined to be between 11.48 and $21.69 \% v / v$. Finally, an in vivo study in Beagle dogs demonstrated the ability of the gastroretentive layer to ensure gastric retention of tablets, especially under fed conditions, thus rendering the developed system a promising technology for a stomach-specific delivery of drugs [105].

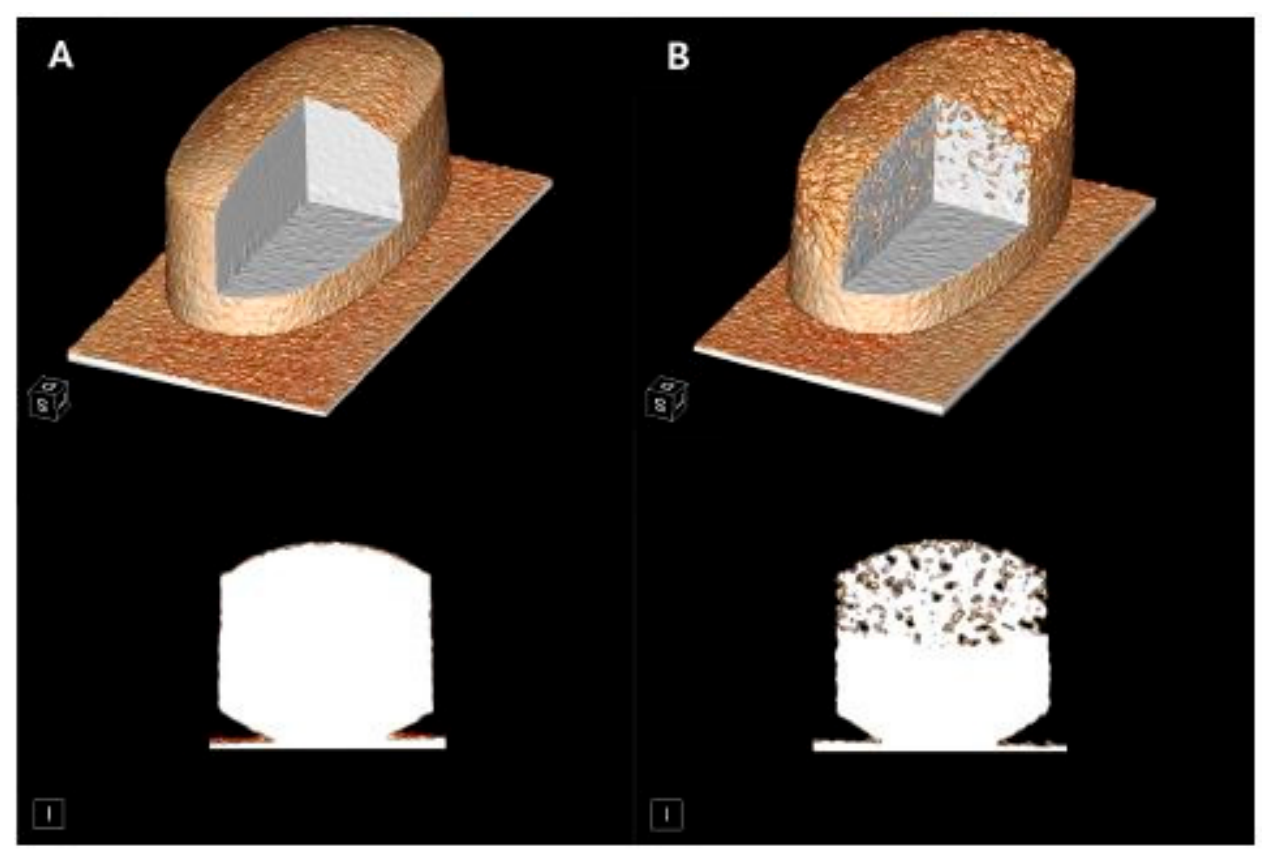

Figure 11. Images from 3D X-ray microcomputed tomography showing the non-porous tablet structure before sublimation (A) and the highly porous structure of the gastroretentive layer of the tablets after sublimation (B). Reprinted from International Journal of Pharmaceutics Vol 572, Hwang et al., Swellable and porous bilayer tablet for gastroretentive drug delivery: Preparation and in vitro-in vivo evaluation, 118783 (Pages 1-13), Copyright 2019, with permission from Elsevier.

Lin et al. developed formulations where PEO and Kollidon ${ }^{\circledR}$ SR were used as release retardants and gastroretentive agents. Single-layer tablets were initially developed, however, despite their floatability, their hardness was too low for practical use, along with a very low drug release extent, therefore they were not forwarded to in vivo studies [87]. Caplets of a similar formulation that were developed did not float, while capsules that contained the same amount of API and excipients showed good swelling and floating behaviour, along with a release of the API over $24 \mathrm{~h}$ [87]. 


\subsubsection{Mucoadhesive and Expandable Systems}

Different studies in the literature have demonstrated the promising capability of mucoadhesive and expandable systems in achieving effective gastric retention for the release of drugs in the upper part of the GIT.

Zentner et al. developed chitosan:PVP hydrogels at a weight ratio of 2:1. The brittle solid mixture swelled extensively (110-115 fold) and rapidly (within less than $3 \mathrm{~h}$ ) when in contact with acidic water ( $\mathrm{pH}$ 2.0) [196]. This system could therefore be promising as an expandable system with mucoadhesive properties that are probably linked to hydrogen and electrostatic interactions between chitosan and the mucus [150,197]. Furthermore, Su et al. developed polyionic complex hydrogels of chitosan with ring-opened (ro) PVP containing alendronate in an attempt to provide a system with improved stability, mucoadhesive and swelling properties that would ensure robust gastric retention in the upper part of the GIT, alongside a controlled release of the drug [47]. Lyophilised powders consisting of different complexes of chitosan of different molecular weights and roPVP prepared via heat application and the addition of sodium hydroxide were compressed into tablets. Mucoadhesive measurements demonstrated a synergistic enhancement of mucoadhesion for chitosan/roPVP complex hydrogels. The viscosity and mucoadhesion force values increased significantly with increasing percentage of chitosan and the complex hydrogels were able to interact more strongly with mucin, compared to chitosan, irrespective of the molecular weight of chitosan. In terms of in vitro drug release, the chitosan/roPVP complex hydrogels of all different chitosan molecular weights provided a 24-h release of alendronate. The release rate increased with increasing swelling ratio of the polymers, and therefore it was suggested that an increase in the gel volume rendered the drug diffusion pathway less hindered, thus increasing the release rate. So, the high-molecular-weight chitosan/roPVP complex hydrogel tablets demonstrated the highest release rate. Finally, an in vivo pharmacokinetic study in rabbits indicated the ability of the high-molecular-weight chitosan/roPVP complex polymer to be successfully retained in the stomach and release alendronate slowly over time, providing increased AUC, half-life and bioavailability values, along with a lower $C_{\max }$ value, compared to a quarter of a Fosamax ${ }^{\circledR}$ tablet. Therefore, the combination of strong swelling and mucoadhesive properties of the chitosan/roPVP complex polymer-based tablets resulted in a new promising formulation that can reduce the risk of alendronate toxicity, along with improving its efficacy [47].

Apart from beads, another potentially efficient bioadhesion and floatation combination technique involves the use of unfolding and swelling polymeric films. Darandale et al. developed a furosemide bilayer capsule formulation consisting of an immediate-release polymeric film and a controlled-release mucoadhesive folded film [198]. Two different formulations were prepared. In case I, the controlled-release film was folded inside the capsule in a zig-zag manner and the immediate-release film was rolled over it, while in case II both films were folded inside the capsule in a zig-zag manner (Figure 12). It was realised that in case II the zig-zag geometry helped the controlled-release film unfold properly in acidic media. The mucoadhesion and controlled release of furosemide from the formulation was achieved mainly due to the presence of Carbopol ${ }^{\circledR}$ 971P, the carboxylic acid groups of which formed hydrogen bonds with the mucus layer of Wistar rat stomach mucosa. Additionally, the presence of HPMC E4M contributed to the swelling of the film and the controlled release of the API which followed Fickian diffusion. Based on its effective unfolding, mucoadhesion and controlled-release properties, the formulation could be most promising in vivo [198]. 

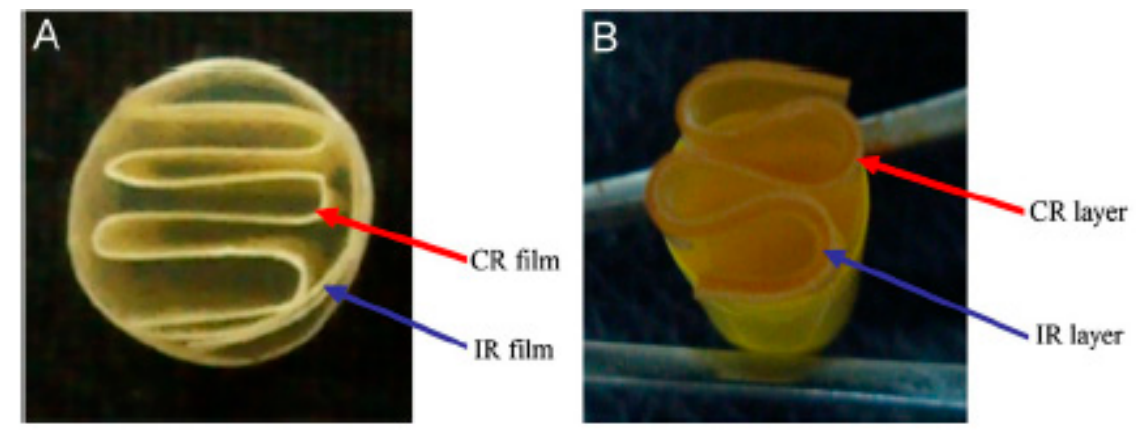

Figure 12. The film folding patterns in case I (A) bilayer capsules where the furosemide immediaterelease film was rolled around the zig-zag-folded controlled-release film and case II (B) bilayer capsule formulations where both films were folded in a zig-zag manner. Reprinted from Acta Pharmaceutica Sinica B Vol 2, Darandale et al., Design of a gastroretentive mucoadhesive dosage form of furosemide for controlled release, Pages 509-517, Copyright 2012, published under a Creative Commons Attribution 3.0 License (https: / / creativecommons.org/licenses/by-nc-nd/3.0/, accessed on 2 August 2021). No changes were made to the original figure presented as Figure 1 in the original research paper.

\subsubsection{Floating and Mucoadhesive Systems}

Various in vitro and in vivo studies have been carried out on the development of mucoadhesive floating drug delivery systems designed to improve gastric residence of drugs through a combination of mucoadhesion and floating mechanisms [2,29,198-200]. In a study, a hollow-bioadhesive microsphere formulation containing glyceryl monooleate as a bioadhesive polymer and psoralen as the model drug was developed [201]. These microspheres showed strong mucoadhesive properties, good buoyancy and a sustained drug release in vitro and in Sprague Dawley rats where an extension of the half-life and a reduction in the elimination rate of the drug were recorded, compared to a psoralen suspension [201].

Karemore et al. focused on the development of a cilnidipine effervescent floating gastroretentive tablet formulation that contained gellan gum as the bioadhesive polymer, as well as HPMC K4M and sodium bicarbonate as excipients that can aid in floatation and controlled drug release [202]. The amounts of these three components had a statistically significant effect on the floating lag time, total floating time, mucoadhesion and in vitro drug release properties of the tablets. An increase in the amount of these components significantly reduced the floating lag time and prolonged the floatation of tablets. This was due to the increased swelling of the polymers, alongside the entrapment of $\mathrm{CO}_{2}$ bubbles generated from the reaction of sodium bicarbonate with hydrochloric acid [202]. Furthermore, sodium bicarbonate acted as a source of sodium ions which promoted the in situ gelation of GG through the formation of a cross-linked, three-dimensional network [203-206]. Regarding the mucoadhesive capability of the tablets, increasing amounts of GG demonstrated an increasing mucoadhesive strength of the tablets onto goat stomach mucosa, due to increased water uptake and swelling and higher availability of adhesive polymer sites that could interact with the mucin molecules. The presence of HPMC K4M significantly enhanced the mucoadhesive strength of the tablets, probably due to a physical entanglement of the two polymers, as well as non-covalent bonding. The drug release was prolonged for $12 \mathrm{~h}$ in vitro with HPMC K4M and GG being the significant factors affecting it. The drug release was found to be governed by non-Fickian diffusion which includes a combination of diffusion and erosion mechanisms. Finally, the tablets demonstrated promising gastric retention and drug release results in human volunteers, indicated by a prolonged half-life and reduced elimination rate of cilnidipine, compared to conventional tablets. These findings further demonstrated the potential of the cilnidipine gastroretentive tablet application [202]. 
Abd El-Aziz et al. developed alfuzosin gastroretentive sponges based on chitosan and HPMC. The sponges proved to be highly porous with density values significantly below $1.004 \mathrm{~g} / \mathrm{cm}^{3}$ which accounted for their immediate floatation [207]. Furthermore, the mucoadhesive force was measured to be higher for the chitosan-based sponges, potentially due to electrostatic interactions between the positively charged amino groups of chitosan and negatively charged sialic acid and mucin. Additionally, the polymer grade and concentration impacted the release of alfuzosin from the system since higher polymer concentration could lead to the formation of a more rigid gel barrier that could reduce water ingress into the matrix, thus reducing the drug release rate. The mechanism of drug release from the optimised sponges was found to be non-Fickian (anomalous) diffusion through a combination of drug diffusion and erosion of the polymeric matrix. Finally, the in vivo gastroretentive potential of the optimised sponges was confirmed in healthy male volunteers [207].

Bera et al. prepared olive oil-entrapped alginate beads containing risperidone, coated with an ionotropically cross-linked alginate-sterculia gum blend gel. The authors believed that this combination would achieve gastric retention through a combination of floatation and mucoadhesion [200]. The uncoated beads were optimised in terms of their drug entrapment efficiency and in vitro drug release. Then, the optimised beads were coated with the blend gel and the coated beads were assessed in terms of their physical properties, buoyancy, in vitro drug release and ex vivo mucoadhesion in the goat stomach mucosa. The results demonstrated that drug entrapment efficiency was significantly dependent on the polymer-to-drug and oil-to-water ratios in the uncoated beads, while drug release rate increased with increasing polymer-to-drug ratio and decreasing oil-to-water ratio. After coating with the ionotropically cross-linked alginate-sterculia gum blend gel, the release of risperidone was successfully retarded over $8 \mathrm{~h}$ in SGF, and it followed a Fickian diffusion-based mechanism. The beads were able to float rapidly due to their low bulk density [200]. The oil entrapment into the beads played a vital role in their buoyancy, due to the formation of multiple pockets within the polymer matrix [208]. The floating lag time decreased with increasing oil content. Furthermore, the swelling and expansion of the polymer matrix further contributed to the buoyancy of the beads via an additional reduction in their density. Finally, the ex vivo study demonstrated an effective adherence of the coated beads onto goat stomach mucosa in an acidic environment, thus rendering the formulation promising as a gastroretentive drug delivery system for risperidone [200]. In another study, Dey et al. developed alginate beads as floating and mucoadhesive GRDDS using sunflower oil as a low-density component to achieve immediate and prolonged buoyancy of the beads, alongside a controlled drug release through the creation of oil pockets in the polymer matrix [199].

Darbasizadeh et al. reported the development and characterisation of ranitidine tripolyphosphate (TPP)-cross-linked chitosan/PEO electrospun nanofibrous mats [12]. The cross-linking process was crucial in ensuring the mechanical stability of the nanofibres and their integrity in aqueous environment given the degradability of the constituent polymers. Furthermore, cross-linking was crucial in ensuring robust mucoadhesive properties of the nanofibres since the cross-linked fibres interacted more strongly and for a significantly longer time with goat stomach mucosa ex vivo, compared to uncross-linked ones. Additionally, the prepared cross-linked nanofibres floated immediately in SGF, due to their high surface area and porosity, and their buoyancy was maintained over more than $24 \mathrm{~h}$. In terms of in vitro drug release, the cross-linked nanofibres demonstrated a reduced burst release, compared to the non-cross-linked ones, and a significantly prolonged release of ranitidine up to $24 \mathrm{~h}$. This was proposed to be due to ionic interactions between tripolyphosphate groups of TPP and ammonium groups of chitosan that may have resulted in reduced mobility and swelling degree of the polymer chains [12]. Therefore, this non-effervescent nanofibre formulation could be promising as a controlled-release gastroretentive delivery system, due to its versatility and its floating and mucoadhesive properties. The potential of cross-linked chitosan and PEO combinations in nanofibre preparation was also reported 
by Abd El Haby et al. who, apart from in vitro and ex vivo characterisation, conducted an in vivo study in rats for the prepared nanofibres. The results demonstrated a robust gastroprotective activity of nizatidine that was significantly more potent when formulated in cross-linked nanofibres, compared to drug solution and uncross-linked nanofibres [209].

\section{Future Considerations}

GRDDS-based controlled-release applications are promising in the oral delivery of drugs that can either act locally towards treating conditions of the upper part of the GIT or act systematically, but may have certain limitations, such as pH-dependent solubility or stability, a narrow window of absorption and/or short half-life. Many gastroretentive controlled-release products are already in the market, with most based on a single-system approach.

All different categories of GRDDS have their limitations. However, the development of systems with combinatory approaches, such as the ones reported in the present review, are promising in achieving a robust behaviour in terms of effective gastric retention and controlled release of different drugs. Furthermore, potential safety issues related to some of the single-approach systems can be addressed through combinatory approaches. The floating and expandable combinatory systems could potentially be the most promising as a technology for the future development of GRDDS since it can offer prolonged GRT via two robust mechanisms of gastric retention without the risk of gastric or bowel obstruction and gastropathy that can be conferred through the use of the expandable systems as an only approach.

In vivo monitoring of the gastric residence of GRDDS is crucial in assessing the gastric retention capability of the gastroretentive formulations. For this purpose, different imaging methods have been employed. These include scintigraphy, X-rays, magnetic resonance imaging (MRI), magnetic moment imaging, gastroscopy and ultrasonography. Each of these imaging techniques has its advantages and limitations [210]. However, these techniques have not been used extensively in the literature to assess the ability of the GRDDS to remain in the stomach for the desired length of time. It is typically considered adequate to simply record the pharmacokinetic profile of drugs after oral administration of the dosage forms and make inferences on the gastric retention capability of the formulations based on the profile parameters. However, in vivo monitoring of the GRDDS is a very important part of the formulation development and should be reported, whenever the appropriate equipment is available.

\section{Conclusions}

The application of GRDDS coupled with controlled-release strategies is a promising approach to improve the therapeutic efficacy and dosing regimen of drugs with solubility, stability, half-life and/or absorption limitations that can treat a wide range of diseases either locally, such as Helicobacter pylori infections, or systemically, such as type 2 diabetes or Parkinson's disease. The anatomy and physiology of the stomach under different states (fasted, fed) and individual patient conditions need to be taken into account during formulation development and clinical use, alongside any critical attributes of the system, based on the chosen approach. There are many different approaches for the development of GRDDS and a few commercially available pharmaceutical products are based on these technologies. However, single-system approaches are accompanied by limitations that could impede a robust formulation behaviour. Combinations of the different technologies could help overcome the limitations of individual approaches, thus rendering these combinatory systems most promising in achieving effective gastric retention and controlled release of a wide range of suitable drugs. The in vivo imaging of gastroretentive formulations can further assist in assessing the robustness of their gastric residence.

Author Contributions: Methodology, N.-N.V., C.J.R. and Z.Z., Validation, N.-N.V.; Analysis, N.-N.V.; Data Curation, N.-N.V.; Writing-Original Draft Preparation, N.-N.V.; Conceptualization, C.J.R. and Z.Z.; Investigation, N.-N.V., C.J.R. and Z.Z.; Writing-Review \& Editing, C.J.R. and Z.Z.; Supervision, 
C.J.R. and Z.Z.; Project Administration and Funding Acquisition, Z.Z. All authors have read and agreed to the published version of the manuscript.

Funding: The authors thank Shenyang Haiwang Biotechnology Co., Limited (Shenyang, China, license number 91210102MAOP4EKG8Y) for the PhD funding for Napoleon-Nikolaos Vrettos.

Institutional Review Board Statement: Not applicable.

Informed Consent Statement: Not applicable.

Data Availability Statement: Not applicable.

Conflicts of Interest: The authors declare no conflict of interest.

\section{References}

1. Yin, L.; Qin, C.; Chen, K.; Zhu, C.; Cao, H.; Zhou, J.; He, W.; Zhang, Q. Gastro-floating tablets of cephalexin: Preparation and in vitro/in vivo evaluation. Int. J. Pharm. 2013, 452, 241-248. [CrossRef] [PubMed]

2. Chen, Y.-C.; Ho, H.-O.; Lee, T.-Y.; Sheu, M.-T. Physical characterizations and sustained release profiling of gastroretentive drug delivery systems with improved floating and swelling capabilities. Int. J. Pharm. 2013, 441, 162-169. [CrossRef] [PubMed]

3. Amit Kumar, N.; Jadupati, M.; Kalyan Kumar, S. Gastroretentive drug delivery technologies: Current approaches and future potential. J. Pharm. Educ. Res. 2010, 1, 1.

4. Gröning, R.; Cloer, C.; Georgarakis, M.; Müller, R.S. Compressed collagen sponges as gastroretentive dosage forms: In vitro and in vivo studies. Eur. J. Pharm. Sci. 2007, 30,1-6. [CrossRef]

5. Lopes, C.M.; Bettencourt, C.; Rossi, A.; Buttini, F.; Barata, P. Overview on gastroretentive drug delivery systems for improving drug bioavailability. Int. J. Pharm. 2016, 510, 144-158. [CrossRef]

6. Gröning, R.; Heun, G. Oral Dosage Forms with Controlled Gastrointestinal Transit. Drug Dev. Ind. Pharm. 1984, 10, 527-539. [CrossRef]

7. Moës, A.J. Gastroretentive dosage forms. Crit. Rev. Ther. Drug Carr. Syst. 1993, 10, 143-195.

8. Deshpande, A.A.; Rhodes, C.T.; Shah, N.H.; Malick, A.W. Controlled-Release Drug Delivery Systems for Prolonged Gastric Residence: An Overview. Drug Dev. Ind. Pharm. 1996, 22, 531-539. [CrossRef]

9. Bardonnet, P.L.; Faivre, V.; Pugh, W.J.; Piffaretti, J.C.; Falson, F. Gastroretentive dosage forms: Overview and special case of Helicobacter pylori. J. Control. Release 2006, 111, 1-18. [CrossRef]

10. Tripathi, J.; Thapa, P.; Maharjan, R.; Jeong, S.H. Current State and Future Perspectives on Gastroretentive Drug Delivery Systems. Pharmaceutics 2019, 11, 193. [CrossRef]

11. Rouge, N.; Buri, P.; Doelker, E. Drug absorption sites in the gastrointestinal tract and dosage forms for site-specific delivery. Int. J. Pharm. 1996, 136, 117-139. [CrossRef]

12. Darbasizadeh, B.; Motasadizadeh, H.; Foroughi-Nia, B.; Farhadnejad, H. Tripolyphosphate-crosslinked chitosan/poly (ethylene oxide) electrospun nanofibrous mats as a floating gastro-retentive delivery system for ranitidine hydrochloride. J. Pharm. Biomed. Anal. 2018, 153, 63-75. [CrossRef] [PubMed]

13. Kim, S.; Hwang, K.-M.; Park, Y.S.; Nguyen, T.-T.; Park, E.-S. Preparation and evaluation of non-effervescent gastroretentive tablets containing pregabalin for once-daily administration and dose proportional pharmacokinetics. Int. J. Pharm. 2018, 550, 160-169. [CrossRef] [PubMed]

14. Hwang, K.-M.; Cho, C.-H.; Tung, N.-T.; Kim, J.-Y.; Rhee, Y.-S.; Park, E.-S. Release kinetics of highly porous floating tablets containing cilostazol. Eur. J. Pharm. Biopharm. 2017, 115, 39-51. [CrossRef] [PubMed]

15. Klausner, E.A.; Lavy, E.; Friedman, M.; Hoffman, A. Expandable gastroretentive dosage forms. J. Control. Release 2003, 90, 143-162. [CrossRef]

16. Thapa, P.; Jeong, S. Effects of Formulation and Process Variables on Gastroretentive Floating Tablets with A High-Dose Soluble Drug and Experimental Design Approach. Pharmaceutics 2018, 10, 161. [CrossRef] [PubMed]

17. Jiménez-Martínez, I.; Quirino-Barreda, T.; Villafuerte-Robles, L. Sustained delivery of captopril from floating matrix tablets. Int. J. Pharm. 2008, 362, 37-43. [CrossRef]

18. El-Zahaby, S.A.; Kassem, A.A.; El-Kamel, A.H. Design and evaluation of gastroretentive levofloxacin floating mini-tablets-incapsule system for eradication of Helicobacter pylori. Saudi Pharm. J. 2014, 22, 570-579. [CrossRef]

19. Sarkar, D.; Nandi, G.; Changder, A.; Hudati, P.; Sarkar, S.; Ghosh, L.K. Sustained release gastroretentive tablet of metformin hydrochloride based on poly (acrylic acid)-grafted-gellan. Int. J. Biol. Macromol. 2017, 96, 137-148. [CrossRef]

20. Sarparanta, M.P.; Bimbo, L.M.; Mäkilä, E.M.; Salonen, J.J.; Laaksonen, P.H.; Helariutta, A.M.K.; Linder, M.B.; Hirvonen, J.T.; Laaksonen, T.J.; Santos, H.A.; et al. The mucoadhesive and gastroretentive properties of hydrophobin-coated porous silicon nanoparticle oral drug delivery systems. Biomaterials 2012, 33, 3353-3362. [CrossRef]

21. He, W.; Li, Y.; Zhang, R.; Wu, Z.; Yin, L. Gastro-floating bilayer tablets for the sustained release of metformin and immediate release of pioglitazone: Preparation and in vitro/in vivo evaluation. Int. J. Pharm. 2014, 476, 223-231. [CrossRef] [PubMed]

22. Michelson, E.L. Calcium Antagonists in Cardiology: Update on Sustained-release Drug Delivery Systems. Clin Cardiol. 1991, 14, 947-950. [CrossRef] [PubMed] 
23. Hutton, J.T.; Morris, J.L. Long-acting carbidopa-levodopa in the management of moderate and advanced Parkinson's disease. Neurology 1992, 42, 51-56, discussion 57-60. [PubMed]

24. Wagstaff, A.J.; Goa, K.L. Once-weekly fluoxetine. Drugs 2001, 61, 2221-2228, discussion 2229-2230. [CrossRef]

25. Michel, M. A Benefit-Risk Assessment of Extended-Release Oxybutynin. Drug Saf. 2002, 25, 867-876. [CrossRef]

26. Pieper, J.A. Understanding niacin formulations. Am. J. Manag. Care 2002, 8, S308.

27. McCarberg, B. Tramadol extended-release in the management of chronic pain. Ther. Clin. Risk Manag. 2007, 3, 401.

28. Patil, H.; Tiwari, R.V.; Repka, M.A. Recent advancements in mucoadhesive floating drug delivery systems: A mini-review. J. Drug Deliv. Sci. Technol. 2016, 31, 65-71. [CrossRef]

29. Shtenberg, Y.; Goldfeder, M.; Prinz, H.; Shainsky, J.; Ghantous, Y.; Abu El-Naaj, I.; Schroeder, A.; Bianco-Peled, H. Mucoadhesive alginate pastes with embedded liposomes for local oral drug delivery. Int. J. Biol. Macromol. 2018, 111, 62-69. [CrossRef]

30. Andrews, G.P.; Laverty, T.P.; Jones, D.S. Mucoadhesive polymeric platforms for controlled drug delivery. Eur. J. Pharm. Biopharm. 2009, 71, 505-518. [CrossRef] [PubMed]

31. Jian Wang, Y.T.Y.D.K.M.Y.T.Y.I. Positively Charged Gelatin Microspheres as Gastric Mucoadhesive Drug Delivery System for Eradication of H. pylori. Drug Deliv. 2000, 7, 237-243. [CrossRef]

32. Bhalla, S.; Nagpal, M. Comparison of Various Generations of Superporous Hydrogels Based on Chitosan-Acrylamide and In Vitro Drug Release. ISRN Pharm. 2013, 2013, 624841. [CrossRef]

33. Omidian, H.; Rocca, J.G.; Park, K. Advances in superporous hydrogels. J. Control. Release 2005, 102, 3-12. [CrossRef]

34. Fujimori, J.; Machida, Y.; Tanaka, S.; Nagai, T. Effect of magnetically controlled gastric residence of sustained release tablets on bioavailability of acetaminophen. Int. J. Pharm. 1995, 119, 47-55. [CrossRef]

35. Gröning, R.; Berntgen, M.; Georgarakis, M. Acyclovir serum concentrations following peroral administration of magnetic depot tablets and the influence of extracorporal magnets to control gastrointestinal transit. Eur. J. Pharm. Biopharm. 1998, 46, 285-291. [CrossRef]

36. Zhou, Y.; Gu, N.; Yang, F. In situ microbubble-assisted, ultrasound-controlled release of superparamagnetic iron oxide nanoparticles from gastro-retentive tablets. Int. J. Pharm. 2020, 586, 119615. [CrossRef] [PubMed]

37. Mahadevan, V. Anatomy of the stomach. Surgery 2014, 32, 571-574. [CrossRef]

38. Horton-Szar, D.; Griffiths, M.; Lombard, M. Gastrointestinal System/Edited by Dan Horton-Szar, 4th ed.; Mosby: Saint Louis, MO, USA, 2012.

39. Soybel, D.I. Anatomy and Physiology of the Stomach. Surg. Clin. N. Am. 2005, 85, 875-894. [CrossRef] [PubMed]

40. Van Den Abeele, J.; Rubbens, J.; Brouwers, J.; Augustijns, P. The dynamic gastric environment and its impact on drug and formulation behaviour. Eur. J. Pharm. Sci. 2017, 96, 207-231. [CrossRef] [PubMed]

41. Prajapati, V.D.; Jani, G.K.; Khutliwala, T.A.; Zala, B.S. Raft forming system-An upcoming approach of gastroretentive drug delivery system. J. Control. Release 2013, 168, 151-165. [CrossRef]

42. Zate, S.; Kothawade, P.; Mahale, G.; Kapse, K.; Anantwar, S. Gastro Retentive Bioadhesive Drug Delivery System: A Review. Int. J. PharmTech Res. 2010, 2.

43. Helliwell, M. The use of bioadhesives in targeted delivery within the gastrointestinal tract. Adv. Drug Deliv. Rev. 1993, 11, 221-251. [CrossRef]

44. Wickham, M.J.S.; Faulks, R.M.; Mann, J.; Mandalari, G. The Design, Operation, and Application of a Dynamic Gastric Model. Dissolution Technol. 2012, 19, 15-22. [CrossRef]

45. Dorożyński, P.; Kulinowski, P.; Mendyk, A.; Jachowicz, R. Gastroretentive drug delivery systems with 1-dopa based on carrageenans and hydroxypropylmethylcellulose. Int. J. Pharm. 2011, 404, 169-175. [CrossRef] [PubMed]

46. Timmermans, J.; Moës, A.J. The Cutoff Size for Gastric Emptying of Dosage Forms. J. Pharm. Sci. 1993, 82, 854. [CrossRef]

47. Su, C.-Y.; Ho, H.-O.; Chen, Y.-C.; Yu, Y.-T.; Liu, D.-Z.; Chao, F.-C.; Sheu, M.-T. Complex Hydrogels Composed of Chitosan with Ring-opened Polyvinyl Pyrrolidone as a Gastroretentive Drug Dosage Form to Enhance the Bioavailability of Bisphosphonates. Sci. Rep. 2018, 8, 8092. [CrossRef] [PubMed]

48. Lele, B.S.; Hoffman, A.S. Mucoadhesive drug carriers based on complexes of poly(acrylic acid) and PEGylated drugs having hydrolysable PEG-anhydride-drug linkages. J. Control. Release 2000, 69, 237-248. [CrossRef]

49. Dressman, J.B.; Reppas, C. Oral Drug Absorption: Prediction and Assessment/Edited by Jennifer B. Dressman, Christos Reppas, 2nd ed.; Informa Healthcare: New York, NY, USA, 2010.

50. Streubel, A.; Siepmann, J.; Bodmeier, R. Gastroretentive drug delivery systems. Expert Opin. Drug Deliv. 2006, 3, 217-233. [CrossRef] [PubMed]

51. Chauhan, M.S.; Kumar, A.; Pathak, K. Osmotically regulated floating asymmetric membrane capsule for controlled site-specific delivery of ranitidine hydrochloride: Optimization by central composite design. AAPS PharmSciTech 2012, 13, $1492-1501$. [CrossRef] [PubMed]

52. Chen, K.; Wen, H.; Yang, F.; Yu, Y.; Gai, X.; Wang, H.; Li, P.; Pan, W.; Yang, X. Study of controlled-release floating tablets of dipyridamole using the dry-coated method. Drug Dev. Ind. Pharm. 2018, 44, 116-124. [CrossRef] [PubMed]

53. Qi, X.; Chen, H.; Rui, Y.; Yang, F.; Ma, N.; Wu, Z. Floating tablets for controlled release of ofloxacin via compression coating of hydroxypropyl cellulose combined with effervescent agent. Int. J. Pharm. 2015, 489, 210-217. [CrossRef] [PubMed]

54. Clarke, G.M.; Newton, J.M.; Short, M.D. Gastrointestinal transit of pellets of differing size and density. Int. J. Pharm. 1993, 100, 81-92. [CrossRef] 
55. Talukder, R.; Fassihi, R. Gastroretentive delivery systems: A mini review. Drug Dev. Ind. Pharm. 2004, 30, 1019-1028. [CrossRef] [PubMed]

56. Streubel, A.; Siepmann, J.; Bodmeier, R. Drug delivery to the upper small intestine window using gastroretentive technologies. Curr. Opin. Pharmacol. 2006, 6, 501-508. [CrossRef] [PubMed]

57. Arora, S.; Ali, J.; Ahuja, A.; Khar, R.K.; Baboota, S. Floating drug delivery systems: A review. AAPS PharmSciTech 2005, 6, E372-E390. [CrossRef]

58. Awasthi, R.; Kulkarni, G.T. Decades of research in drug targeting to the upper gastrointestinal tract using gastroretention technologies: Where do we stand? Drug Deliv. 2016, 23, 378-394. [CrossRef]

59. Shaha, S.H.; Patel, J.K.; Pundarikakshudu, K. An overview of a gastro-retentive floating drug delivery system. Asian J. Pharm. 2009, 4, 65-80.

60. Calbet, J.A.; MacLean, D.A. Role of caloric content on gastric emptying in humans. J. Physiol. 1997, 498 (Pt 2), 553-559. [CrossRef]

61. Juvonen, K.R.; Purhonen, A.K.; Salmenkallio-Marttila, M.; Lähteenmäki, L.; Laaksonen, D.E.; Herzig, K.H.; Uusitupa, M.I.; Poutanen, K.S.; Karhunen, L.J. Viscosity of oat bran-enriched beverages influences gastrointestinal hormonal responses in healthy humans. J. Nutr. 2009, 139, 461-466. [CrossRef]

62. Zhu, Y.; Hsu, W.H.; Hollis, J.H. The impact of food viscosity on eating rate, subjective appetite, glycemic response and gastric emptying rate. PLoS ONE 2013, 8, e67482. [CrossRef]

63. Garg, R.; Gupta, G.D. Progress in Controlled Gastroretentive Delivery Systems. Trop. J. Pharm. Res. 2008, 7. [CrossRef]

64. Nguyen, N.Q.; Debreceni, T.L.; Burgstad, C.M.; Wishart, J.M.; Bellon, M.; Rayner, C.K.; Wittert, G.A.; Horowitz, M. Effects of Posture and Meal Volume on Gastric Emptying, Intestinal Transit, Oral Glucose Tolerance, Blood Pressure and Gastrointestinal Symptoms After Roux-en-Y Gastric Bypass. Obes. Surg. 2015, 25, 1392-1400. [CrossRef] [PubMed]

65. Mojaverian, P.; Vlasses, P.H.; Kellner, P.E.; Rocci, M.L., Jr. Effects of gender, posture, and age on gastric residence time of an indigestible solid: Pharmaceutical considerations. Pharm. Res. 1988, 5, 639-644. [CrossRef] [PubMed]

66. Wang, Y.T.; Mohammed, S.D.; Farmer, A.D.; Wang, D.; Zarate, N.; Hobson, A.R.; Hellström, P.M.; Semler, J.R.; Kuo, B.; Rao, S.S.; et al. Regional gastrointestinal transit and $\mathrm{pH}$ studied in 215 healthy volunteers using the wireless motility capsule: Influence of age, gender, study country and testing protocol. Aliment. Pharm. Ther. 2015, 42, 761-772. [CrossRef] [PubMed]

67. Wald, A.; Van Thiel, D.H.; Hoechstetter, L.; Gavaler, J.S.; Egler, K.M.; Verm, R.; Scott, L.; Lester, R. Gastrointestinal transit: The effect of the menstrual cycle. Gastroenterology 1981, 80, 1497-1500. [CrossRef]

68. Krygowska-Wajs, A.; Cheshire, W.P., Jr.; Wszolek, Z.K.; Hubalewska-Dydejczyk, A.; Jasinska-Myga, B.; Farrer, M.J.; Moskala, M.; Sowa-Staszczak, A. Evaluation of gastric emptying in familial and sporadic Parkinson disease. Parkinsonism Relat. Disord. 2009, 15, 692-696. [CrossRef] [PubMed]

69. Triantafyllou, K.; Kalantzis, C.; Papadopoulos, A.A.; Apostolopoulos, P.; Rokkas, T.; Kalantzis, N.; Ladas, S.D. Video-capsule endoscopy gastric and small bowel transit time and completeness of the examination in patients with diabetes mellitus. Dig. Liver Dis. 2007, 39, 575-580. [CrossRef]

70. Choi, B.Y.; Park, H.J.; Hwang, S.J.; Park, J.B. Preparation of alginate beads for floating drug delivery system: Effects of CO2 gas-forming agents. Int. J. Pharm. 2002, 239, 81-91. [CrossRef]

71. Rossi, A.; Conti, C.; Colombo, G.; Castrati, L.; Scarpignato, C.; Barata, P.; Sandri, G.; Caramella, C.; Bettini, R.; Buttini, F.; et al. Floating modular drug delivery systems with buoyancy independent of release mechanisms to sustain amoxicillin and clarithromycin intra-gastric concentrations. Drug Dev. Ind. Pharm. 2016, 42, 332-339. [CrossRef]

72. Nguyen, T.-T.; Hwang, K.-M.; Kim, S.-H.; Park, E.-S. Development of novel bilayer gastroretentive tablets based on hydrophobic polymers. Int. J. Pharm. 2020, 574. [CrossRef]

73. Verma, A.D.J.; Verma, N.; Nayak, A.K. Chitosan-Hydroxypropyl Methylcellulose Matrices as Carriers for Hydrodynamically Balanced Capsules of Moxifloxacin HCl. Curr. Drug Deliv. 2017, 14, 83-90. [CrossRef]

74. Nayak, A.K.; Das, B.; Maji, R. Gastroretentive hydrodynamically balanced systems of ofloxacin: In vitro evaluation. Saudi Pharm. J. 2013, 21, 113-117. [CrossRef]

75. Reddy, L.H.V.; Murthy, R.S.R. Floating Dosage Systems in Drug Delivery. Ther. Drug Carr. Syst. 2002, 19, 36. [CrossRef]

76. Hwang, S.J.; Park, H.; Park, K. Gastric retentive drug-delivery systems. Crit Rev. Ther. Drug Carr. Syst 1998, 15, $243-284$.

77. Nayak, A.K.; Malakar, J. Formulation and in vitro evaluation of Hydrodynamically balanced system for theophylline delivery. J. Basic Clin. Pharm. 2011, 2, 133-137. [PubMed]

78. Patra, C.N.; Kumar, A.B.; Pandit, H.K.; Singh, S.P.; Devi, M.V. Design and evaluation of sustained release bilayer tablets of propranolol hydrochloride. Acta Pharm. 2007, 57, 479. [CrossRef] [PubMed]

79. Tiwari, S.B.; Murthy, T.K.; Raveendra Pai, M.; Mehta, P.R.; Chowdary, P.B. Controlled release formulation of tramadol hydrochloride using hydrophilic and hydrophobic matrix system. AAPS PharmSciTech 2003, 4, 18-23. [CrossRef]

80. Erni, W.; Held, K. The Hydrodynamically Balanced System: A Novel Principle of Controlled Drug Release. Eur. Neurol. 1987, 27 (Suppl. 1), 21-27. [CrossRef]

81. Jansen, E.N.; Meerwaldtt, J.D. Madopar HBS in nocturnal symptoms of Parkinson's disease. Adv. Neurol 1990, 53, 527-531.

82. Koller, W.C.; Pahwa, R. Treating motor fluctuations with controlled-release levodopa preparations. Neurology 1994, 44, S23-S28.

83. Oth, M.; Franz, M.; Timmermans, J.; Möes, A. The bilayer floating capsule: A stomach-directed drug delivery system for misoprostol. Pharm. Res. 1992, 9, 298-302. [CrossRef] [PubMed] 
84. Krogel, I.; Bodmeier, R. Development of a multifunctional matrix drug delivery system surrounded by an impermeable cylinder. J. Control. Release 1999, 61, 43-50. [CrossRef]

85. Qin, C.; Wu, M.; Xu, S.; Wang, X.; Shi, W.; Dong, Y.; Yang, L.; He, W.; Han, X.; Yin, L. Design and optimization of gastro-floating sustained-release tablet of pregabalin: In vitro and in vivo evaluation. Int. J. Pharm. 2018, 545, 37-44. [CrossRef]

86. Mehta, D.M.; Parejiya, P.B.; Patel, H.K.; Trivedi, P.J.; Suthar, D.D.; Shelat, P.K. Design, optimization and pharmacokinetics of novel prolonged gastroretentive drug delivery system of quetiapine fumarate. J. Pharm. Investig. 2016, 46, 453-465. [CrossRef]

87. Lin, H.-L.; Chen, L.-C.; Cheng, W.-T.; Cheng, W.-J.; Ho, H.-O.; Sheu, M.-T. Preparation and Characterization of a Novel Swellable and Floating Gastroretentive Drug Delivery System (sfGRDDS) for Enhanced Oral Bioavailability of Nilotinib. Pharmaceutics 2020, 12, 137. [CrossRef] [PubMed]

88. Raza, A.; Hayat, U.; Wang, H.-J.; Wang, J.-Y. Preparation and evaluation of captopril loaded gastro-retentive zein based porous floating tablets. Int. J. Pharm. 2020, 579, 119185. [CrossRef]

89. Oh, J.-H.; Eun Lee, J.; Jeong Kim, Y.; Oh, T.-O.; Han, S.; Jeon, E.K.; Shin, K.; Kim, D.-H.; Hye Park, C.; Lee, Y.-J. Designing of the fixed-dose gastroretentive bilayer tablet for sustained release of metformin and immediate release of atorvastatin. Drug Dev. Ind. Pharm. 2016, 42, 340-349. [CrossRef] [PubMed]

90. Oh, T.-O.; Kim, J.-Y.; Ha, J.-M.; Chi, S.-C.; Rhee, Y.-S.; Park, C.-W.; Park, E.-S. Preparation of highly porous gastroretentive metformin tablets using a sublimation method. Eur. J. Pharm. Biopharm. 2013, 83, 460-467. [CrossRef] [PubMed]

91. Sako, K.; Mizumoto, T.; Kajiyama, A.; Ohmura, T. Influence of physical factors in gastrointestinal tract on acetaminophen release from controlled-release tablets in fasted dogs. Int. J. Pharm. 1996, 137, 225-232. [CrossRef]

92. Hajare PP, R.P. Gastroretentive microballoons: A novel approach for drug delivery. Int. J. Pharm. Sci. Res. 2020, 11, $1075-1083$.

93. Maghsoodi, M.; Hemati, E.; Qadermazi, B.; Yari, Z. Hollow microspheres for gastroretentive floating- pulsatile drug delivery: Preparation and in vitro evaluation. Adv. Pharm. Bull. 2011, 1,55-61. [CrossRef]

94. Kawashima, Y.; Niwa, T.; Takeuchi, H.; Hino, T.; Itoh, Y. Hollow microspheres for use as a floating controlled drug delivery system in the stomach. J. Pharm. Sci. 1992, 81, 135-140. [CrossRef]

95. Jayanthi, G.; Jayaswal, S.B.; Srivastava, A.K. Formulation and evaluation of terfenadine microballoons for oral controlled release. Pharmazie 1995, 50, 769-770. [PubMed]

96. Sato, Y.; Kawashima, Y.; Takeuchi, H.; Yamamoto, H. In vivo evaluation of riboflavin-containing microballoons for floating controlled drug delivery system in healthy human volunteers. J. Control. Release 2003, 93, 39-47. [CrossRef]

97. Sato, Y.; Kawashima, Y.; Takeuchi, H.; Yamamoto, H. In vitro and in vivo evaluation of riboflavin-containing microballoons for a floating controlled drug delivery system in healthy humans. Int. J. Pharm. 2004, 275, 97-107. [CrossRef]

98. Sato, Y.; Kawashima, Y.; Takeuchi, H.; Yamamoto, H.; Fujibayashi, Y. Pharmacoscintigraphic evaluation of riboflavin-containing microballoons for a floating controlled drug delivery system in healthy humans. J. Control. Release 2004, 98, 75-85. [CrossRef] [PubMed]

99. Ammar, H.O.; Ghorab, M.; Kamel, R.; Salama, A.H. Design and optimization of gastro-retentive microballoons for enhanced bioavailability of cinnarizine. Drug Deliv. Transl. Res. 2016, 6, 210-224. [CrossRef]

100. Tadros, M.I.; Fahmy, R.H. Controlled-release triple anti-inflammatory therapy based on novel gastroretentive sponges: Characterization and magnetic resonance imaging in healthy volunteers. Int. J. Pharm. 2014, 472, 27-39. [CrossRef]

101. Siepmann, J.; Streubel, A.; Peppas, N.A. Understanding and Predicting Drug Delivery from Hydrophilic Matrix Tablets Using the "Sequential Layer" Model. Pharm. Res. 2002, 19, 306-314. [CrossRef]

102. Rahim, S.A.; Carter, P.; Elkordy, A.A. Influence of calcium carbonate and sodium carbonate gassing agents on pentoxifylline floating tablets properties. Powder Technol. 2017, 322, 65-74. [CrossRef]

103. Baumgartner, S.; Kristl, J.; Vrečer, F.; Vodopivec, P.; Zorko, B. Optimisation of floating matrix tablets and evaluation of their gastric residence time. Int. J. Pharm. 2000, 195, 125-135. [CrossRef]

104. Raza, A.; Shen, N.; Li, J.; Chen, Y.; Wang, J.-Y. Formulation of zein based compression coated floating tablets for enhanced gastric retention and tunable drug release. Eur. J. Pharm. Sci. 2019, 132, 163-173. [CrossRef]

105. Hwang, K.-M.; Nguyen, T.-T.; Seok, S.H.; Jo, H.-I.; Cho, C.-H.; Hwang, K.-M.; Kim, J.-Y.; Park, C.-W.; Rhee, Y.-S.; Park, E.-S. Swellable and porous bilayer tablet for gastroretentive drug delivery: Preparation and in vitro-in vivo evaluation. Int. J. Pharm. 2019, 572, 118783. [CrossRef]

106. Diós, P.; Nagy, S.; Pál, S.; Pernecker, T.; Kocsis, B.; Budán, F.; Horváth, I.; Szigeti, K.; Bölcskei, K.; Máthé, D.; et al. Preformulation studies and optimization of sodium alginate based floating drug delivery system for eradication of Helicobacter pylori. Eur. J. Pharm. Biopharm. 2015, 96, 196-206. [CrossRef]

107. Han, D.; Steckl, A.J. Triaxial Electrospun Nanofiber Membranes for Controlled Dual Release of Functional Molecules. ACS Appl. Mater. Interfaces 2013, 5, 8241-8245. [CrossRef] [PubMed]

108. Han, D.; Yu, X.; Chai, Q.; Ayres, N.; Steckl, A.J. Stimuli-Responsive Self-Immolative Polymer Nanofiber Membranes Formed by Coaxial Electrospinning. ACS Appl. Mater. Interfaces 2017, 9, 11858-11865. [CrossRef] [PubMed]

109. Hu, X.; Liu, S.; Zhou, G.; Huang, Y.; Xie, Z.; Jing, X. Electrospinning of polymeric nanofibers for drug delivery applications. J. Control. Release 2014, 185, 12-21. [CrossRef]

110. Palo, M.; Kogermann, K.; Laidmäe, I.; Meos, A.; Preis, M.; Heinämäki, J.; Sandler, N. Development of Oromucosal Dosage Forms by Combining Electrospinning and Inkjet Printing. Mol. Pharm. 2017, 14, 808-820. [CrossRef] 
111. Adibkia, K.; Hamedeyazdan, S.; Javadzadeh, Y. Drug release kinetics and physicochemical characteristics of floating drug delivery systems. Expert Opin. Drug Deliv. 2011, 8, 891-903. [CrossRef] [PubMed]

112. Malik, R.; Garg, T.; Goyal, A.K.; Rath, G. Polymeric nanofibers: Targeted gastro-retentive drug delivery systems. J. Drug Target. 2015, 23, 109-124. [CrossRef]

113. Tort, S.; Han, D.; Steckl, A.J. Self-inflating floating nanofiber membranes for controlled drug delivery. Int. J. Pharm. 2020, 579, 119164. [CrossRef]

114. Abou Youssef, N.A.H.; Kassem, A.A.; El-Massik, M.A.E.; Boraie, N.A. Development of gastroretentive metronidazole floating raft system for targeting Helicobacter pylori. Int. J. Pharm. 2015, 486, 297-305. [CrossRef]

115. Kerdsakundee, N.; Mahattanadul, S.; Wiwattanapatapee, R. Development and evaluation of gastroretentive raft forming systems incorporating curcumin-Eudragit®EPO solid dispersions for gastric ulcer treatment. Eur. J. Pharm. Biopharm. 2015, 94, 513-520. [CrossRef]

116. Lambert, J.R.; Korman, M.G.; Nicholson, L.; Chan, J.G. In-vivo anti-reflux and raft properties of alginates. Aliment. Pharm. Ther. 1990, 4, 615-622. [CrossRef] [PubMed]

117. Hampson, F.C.; Jolliffe, I.G.; Bakhtyari, A.; Taylor, G.; Sykes, J.; Johnstone, L.M.; Dettmar, P.W. Alginate-antacid combinations: Raft formation and gastric retention studies. Drug Dev. Ind. Pharm. 2010, 36, 614-623. [CrossRef]

118. Abouelatta, S.M.; Aboelwafa, A.A.; El-Gazayerly, O.N. Gastroretentive raft liquid delivery system as a new approach to release extension for carrier-mediated drug. Drug Deliv. 2018, 25, 1161-1174. [CrossRef] [PubMed]

119. Fabregas, J.L.; Claramunt, J.; Cucala, J.; Pous, R.; Siles, A. “In-Vitro" Testing of an Antacid Formulation with Prolonged Gastric Residence Time (Almagate Flot-Coat $\left.{ }^{\circledR}\right)$. Drug Dev. Ind. Pharm. 1994, 20, 1199-1212. [CrossRef]

120. Nabarawi El, M.A.; Teaima, M.H.; Abd El-Monem, R.A.; El Nabarawy, N.A.; Gaber, D.A. Formulation, release characteristics, and bioavailability study of gastroretentive floating matrix tablet and floating raft system of Mebeverine HCl. Drug Des. Dev. Ther. 2017, 11, 1081-1093. [CrossRef]

121. Cheng, C.L.; Koo, M.W. Effects of Centella asiatica on ethanol induced gastric mucosal lesions in rats. Life Sci. 2000, 67, 2647-2653. [CrossRef]

122. Wannasarit, S.; Mahattanadul, S.; Issarachot, O.; Puttarak, P.; Wiwattanapatapee, R. Raft-forming gastro-retentive formulations based on Centella asiatica extract-solid dispersions for gastric ulcer treatment. Eur. J. Pharm. Sci. 2020, 143, 105204. [CrossRef] [PubMed]

123. Hampson, F.C.; Farndale, A.; Strugala, V.; Sykes, J.; Jolliffe, I.G.; Dettmar, P.W. Alginate rafts and their characterisation. Int. J. Pharm. 2005, 294, 137-147. [CrossRef]

124. Hanif, M.; Shah, S.; Rasul, A.; Abbas, G.; Zaman, M.; Amjad, M.W.; Abdul Ghafoor Raja, M.; Khan, H.U.; Ashfaq, M.; Iqbal, O. Enhancement of Oral Bioavailability of Ibandronate Through Gastroretentive Raft Forming Drug Delivery System: In Vitro and In Vivo Evaluation. Int. J. Nanomed. 2020, 15, 4847-4858. [CrossRef] [PubMed]

125. Awad, H.; Aboul-Enein, H.Y. A Validated HPLC Assay Method for the Determination of Sodium Alginate in Pharmaceutical Formulations. J. Chromatogr. Sci. 2013, 51, 208-214. [CrossRef] [PubMed]

126. Desai, N.; Purohit, R. Development of Novel High Density Gastroretentive Multiparticulate Pulsatile Tablet of Clopidogrel Bisulfate Using Quality by Design Approach. AAPS PharmSciTech 2017, 18, 3208-3218. [CrossRef]

127. Sharma, A.; Goyal, A.K.; Rath, G. Development and Characterization of Gastroretentive High-Density Pellets Lodged With Zero Valent Iron Nanoparticles. J. Pharm. Sci. 2018, 107, 2663-2673. [CrossRef] [PubMed]

128. Kinloch, A.J. The science of adhesion. J. Mater. Sci. 1982, 17, 617-651. [CrossRef]

129. Smart, J. The basics and underlying mechanisms of mucoadhesion. Adv. Drug Deliv. Rev. 2005, 57, 1556-1568. [CrossRef]

130. Dodou, D.; Breedveld, P.; Wieringa, P.A. Mucoadhesives in the gastrointestinal tract: Revisiting the literature for novel applications. Eur. J. Pharm. Biopharm. 2005, 60,1-16. [CrossRef]

131. Jiménez-castellanos, M.R.; Zia, H.; Rhodes, C.T. Mucoadhesive Drug Delivery Systems. Drug Dev. Ind. Pharm. 1993, 19, 143-194. [CrossRef]

132. Lee, J.W.; Park, J.H.; Robinson, J.R. Bioadhesive-based dosage forms: The next generation. J. Pharm. Sci. 2000, 89, 850-866. [CrossRef]

133. Ugwoke, M.I.; Agu, R.U.; Verbeke, N.; Kinget, R. Nasal mucoadhesive drug delivery: Background, applications, trends and future perspectives. Adv. Drug Deliv. Rev. 2005, 57, 1640-1665. [CrossRef]

134. Ahagon, A.; Gent, A.N. Effect of interfacial bonding on the strength of adhesion. J. Polym. Sci. Polym. Phys. Ed. 1975, 13, 1285-1300. [CrossRef]

135. Vasir, J.K.; Tambwekar, K.; Garg, S. Bioadhesive microspheres as a controlled drug delivery system. Int. J. Pharm. 2003, 255, 13-32. [CrossRef]

136. Campion, R.P. The Influence of Structure on Autohesion (Self-Tack) and other forms of Diffusion into Polymers. J. Adhes. 1975, 7, 1-23. [CrossRef]

137. Voyutskii, S.S.; Voiutskii, S.S. Autohesion and Adhesion of High Polymers; Interscience Publishers: New York, NY, USA, 1963.

138. Wake, W.C. Theories of adhesion and uses of adhesives: A review. Polymer 1978, 19, 291-308. [CrossRef]

139. Jabbari, E.; Peppas, N.A. A model for interdiffusion at interfaces of polymers with dissimilar physical properties. Polymer 1995, 36, 575-586. [CrossRef]

140. Ludwig, A. The use of mucoadhesive polymers in ocular drug delivery. Adv. Drug Deliv. Rev. 2005, 57, 1595-1639. [CrossRef] 
141. Chen JL, C.G. Compositions producing adhesion through hydration. In Adhesion in Biological Systems; Manly, R.S., Ed.; Academic Press: New York, NY, USA, 1970; pp. 163-181.

142. Illum, L. Chitosan and its use as a pharmaceutical excipient. Pharm. Res. 1998, 15, 1326-1331. [CrossRef]

143. Nakatsuka, S.; Andrady, A.L. Permeability of vitamin B-12 in chitosan membranes. Effect of crosslinking and blending with poly(vinyl alcohol) on permeability. J. Appl. Polym. Sci. 1992, 44, 17-28. [CrossRef]

144. Vishal Gupta, N.; Shivakumar, H.G. Preparation and characterization of superporous hydrogels as gastroretentive drug delivery system for rosiglitazone maleate. DARU 2010, 18, 200-210.

145. Alvarez-Lorenzo, C.; Blanco-Fernandez, B.; Puga, A.M.; Concheiro, A. Crosslinked ionic polysaccharides for stimuli-sensitive drug delivery. Adv. Drug Deliv. Rev. 2013, 65, 1148-1171. [CrossRef]

146. Inouye, K.; Machida, Y.; Sannan, T.; Nagai, T. Buoyant sustained release tablets based on chitosan. Drug Des. Deliv. 1988, 2, 165-175.

147. Chandy, T.; Sharma, C.P. Chitosan matrix for oral sustained delivery of ampicillin. Biomaterials 1993, 14, 939-944. [CrossRef]

148. Patel, V.R.; Amiji, M.M. Preparation and Characterization of Freeze-dried Chitosan-Poly(Ethylene Oxide) Hydrogels for SiteSpecific Antibiotic Delivery in the Stomach. Pharm. Res. 1996, 13, 588-593. [CrossRef] [PubMed]

149. Gupta, K.C.; Ravi Kumar, M.N. Drug release behavior of beads and microgranules of chitosan. Biomaterials 2000, 21, 1115-1119. [CrossRef]

150. Souza, M.P.C.; Sábio, R.M.; Ribeiro, T.C.; Santos, A.M.D.; Meneguin, A.B.; Chorilli, M. Highlighting the impact of chitosan on the development of gastroretentive drug delivery systems. Int. J. Biol. Macromol. 2020, 159, 804-822. [CrossRef] [PubMed]

151. Khattab, A.; Zaki, N. Optimization and Evaluation of Gastroretentive Ranitidine HCl Microspheres by Using Factorial Design with Improved Bioavailability and Mucosal Integrity in Ulcer Model. AAPS PharmSciTech 2017, 18, 957-973. [CrossRef]

152. Hou, J.Y.; Gao, L.N.; Meng, F.Y.; Cui, Y.L. Mucoadhesive microparticles for gastroretentive delivery: Preparation, biodistribution and targeting evaluation. Mar. Drugs 2014, 12, 5764-5787. [CrossRef]

153. Ruiz-Caro, R.; Gago-Guillan, M.; Otero-Espinar, F.J.; Veiga, M.D. Mucoadhesive tablets for controlled release of acyclovir. Chem. Pharm. Bull. 2012, 60, 1249. [CrossRef]

154. Salonen, J.; Kaukonen, A.M.; Hirvonen, J.; Lehto, V.P. Mesoporous silicon in drug delivery applications. J. Pharm. Sci. 2008, 97, 632-653. [CrossRef]

155. Prestidge, C.A.; Barnes, T.J.; Lau, C.H.; Barnett, C.; Loni, A.; Canham, L. Mesoporous silicon: A platform for the delivery of therapeutics. Expert Opin. Drug Deliv. 2007, 4, 101-110. [CrossRef]

156. El-Zahaby, S.A.; Kassem, A.A.; El-Kamel, A.H. Formulation and in vitro evaluation of size expanding gastro-retentive systems of levofloxacin hemihydrate. Int. J. Pharm. 2014, 464, 10-18. [CrossRef] [PubMed]

157. Salessiotis, N. Measurement of the diameter of the pylorus in man: Part I. Experimental project for clinical application. Am. J. Surg. 1972, 124, 331-333. [CrossRef]

158. Lalloo, A.K.; McConnell, E.L.; Jin, L.; Elkes, R.; Seiler, C.; Wu, Y. Decoupling the role of image size and calorie intake on gastric retention of swelling-based gastric retentive formulations: Pre-screening in the dog model. Int. J. Pharm. 2012, 431, 90-100. [CrossRef] [PubMed]

159. Mandal, U.K.; Chatterjee, B.; Senjoti, F.G. Gastro-retentive drug delivery systems and their in vivo success: A recent update. Asian J. Pharmceutical Sci. 2016, 11, 575-584. [CrossRef]

160. Sivaneswari, S.; Karthikeyan, E.; Chandana, P.J. Novel expandable gastro retentive system by unfolding mechanism of levetiracetam using simple lattice design-Formulation optimization and in vitro evaluation. Bull. Fac. Pharm. Cairo Univ. 2017, 55, 63-72. [CrossRef]

161. Rimawi, I.B.; Muqedi, R.H.; Kanaze, F.I. Development of Gabapentin Expandable Gastroretentive Controlled Drug Delivery System. Sci. Rep. 2019, 9, 11675. [CrossRef]

162. Dey, S.; Chattopadhyay, S.; Mazumder, B. Formulation and Evaluation of Fixed-Dose Combination of Bilayer Gastroretentive Matrix Tablet Containing Atorvastatin as Fast-Release and Atenolol as Sustained-Release. BioMed Res. Int. 2014, 2014, 396106396112. [CrossRef]

163. Bellinger, A.M.; Jafari, M.; Grant, T.M.; Zhang, S.; Slater, H.C.; Wenger, E.A.; Mo, S.; Lee, Y.-A.L.; Mazdiyasni, H.; Kogan, L.; et al. Oral, ultra-long-lasting drug delivery: Application toward malaria elimination goals. Sci. Transl. Med. 2016, 8, $365 \mathrm{ra157.}$ [CrossRef]

164. Traverso, G.; Langer, R. Perspective: Special delivery for the gut. Nature 2015, 519, S19. [CrossRef]

165. Kirtane, A.R.; Abouzid, O.; Minahan, D.; Bensel, T.; Hill, A.L.; Selinger, C.; Bershteyn, A.; Craig, M.; Mo, S.S.; Mazdiyasni, H.; et al. Development of an oral once-weekly drug delivery system for HIV antiretroviral therapy. Nat. Commun. 2018, 9, 2. [CrossRef] [PubMed]

166. Lyndra Therapeutics. 19 July 2021-Lyndra Therapeutics Announces Positive Outcome of End-of-Phase 2 Meeting with the FDA for Lyndra's Weekly Risperidone (LYN-005) for the Treatment of Adults with Schizophrenia and Other Indications. Available online: www.lyndra.com (accessed on 23 July 2021).

167. Lyndra Therapeutics. 21 January 2021-Lyndra Therapeutics Announces First Subjects Dosed in Phase 1 Clinical Trial of Once-Weekly Rosuvastatin Extended-Release Capsule, LYN-047. Available online: www.lyndra.com (accessed on 23 July 2021). 
168. Lyndra Therapeutics. 6 May 2021-Lyndra Therapeutics Receives FDA Clearance of Investigational New Drug Application for LYN-014, its Once-Weekly Oral Levomethadone Treatment in Development for Opioid Use Disorder. Available online: www.lyndra.com (accessed on 23 July 2021).

169. Chen, J.; Park, H.; Park, K. Synthesis of superporous hydrogels: Hydrogels with fast swelling and superabsorbent properties. J. Biomed. Mater. Res. 1999, 44, 53-62. [CrossRef]

170. Askari, F.; Nafisi, S.; Omidian, H.; Hashemi, S.A. Synthesis and characterization of acrylic-based superabsorbents. J. Appl. Polym. Sci. 1993, 50, 1851-1855. [CrossRef]

171. Omidian, H.; Park, K.; Rocca, J.G. Recent developments in superporous hydrogels. J. Pharm. Pharmacol. 2007, 59, 317-327. [CrossRef]

172. Omidian, H.; Rocca, J.G.; Park, K. Elastic, Superporous Hydrogel Hybrids of Polyacrylamide and Sodium Alginate. Macromol. Biosci. 2006, 6, 703-710. [CrossRef] [PubMed]

173. Guan, J.; Zhou, L.; Nie, S.; Yan, T.; Tang, X.; Pan, W. A novel gastric-resident osmotic pump tablet: In vitro and in vivo evaluation. Int. J. Pharm. 2010, 383, 30-36. [CrossRef] [PubMed]

174. Liu, L.; Wang, J.; Zhu, S. Delivery of prazosin hydrochloride from osmotic pump system prepared by coating the core tablet with an indentation. Drug Deliv. 2007, 14, 219-224. [CrossRef] [PubMed]

175. Chueh, H.R.; Zia, H.; Rhodes, C.T. Optimization of Sotalol Floating and Bioadhesive Extended Release Tablet Formulations. Drug Dev. Ind. Pharm. 1995, 21, 1725-1747. [CrossRef]

176. Iannuccelli, V.; Coppi, G.; Bernabei, M.T.; Cameroni, R. Air compartment multiple-unit system for prolonged gastric residence. Part I. Formulation study. Int. J. Pharm. 1998, 174, 47-54. [CrossRef]

177. Guan, J.; Zhou, L.; Pan, Y.; Han, H.; Xu, H.; Pan, W. A Novel Gastro-Retentive Osmotic Pump Capsule Using Asymmetric Membrane Technology: In Vitro and In Vivo Evaluation. Pharm. Res. 2009, 27, 105. [CrossRef]

178. POLYOX Water-Soluble Resins Dissolving Techniques; The Dow Chemical Company: Midland, MI, USA, 2003; Form No. 326-000020303 AMS.

179. Desai, N.; Purohit, R. Design and Development of Clopidogrel Bisulfate Gastroretentive Osmotic Formulation Using Quality by Design Tools. AAPS PharmSciTech 2017, 18, 2626-2638. [CrossRef]

180. Neumann, M.; Heimhardt, C.; Seidlitz, K.; Koziolek, M.; Schneider, F.; Schiller, C.; Hanke, U.; Anschütz, M.; Knopke, C.; Donath, F.; et al. Development of a furosemide-containing expandable system for gastric retention. J. Control. Release 2021, 338, 105-118. [CrossRef] [PubMed]

181. Neumann, M.; Schneider, F.; Koziolek, M.; Garbacz, G.; Weitschies, W. A novel mechanical antrum model for the prediction of the gastroretentive potential of dosage forms. Int. J. Pharm. 2017, 530, 63-70. [CrossRef] [PubMed]

182. Guo, X.; Chang, R.-K.; Hussain, M.A. Ion-exchange resins as drug delivery carriers. J. Pharm. Sci. 2009, 98, 3886-3902. [CrossRef] [PubMed]

183. Sriwongjanya, M.; Bodmeier, R. Effect of ion exchange resins on the drug release from matrix tablets. Eur. J. Pharm. Biopharm. 1998, 46, 321-327. [CrossRef]

184. Borodkin, S.; Sundberg, D.P. Polycarboxylic acid ion-exchange resin adsorbates for taste coverage in chewable tablets. J. Pharm. Sci. 1971, 60, 1523-1527. [CrossRef]

185. Zhang, Z.-Y.; Ping, Q.-N.; Xiao, B. Microencapsulation and characterization of tramadol-resin complexes. J. Control. Release 2000, 66, 107-113. [CrossRef]

186. Jeong, S.H.; Park, K. Drug loading and release properties of ion-exchange resin complexes as a drug delivery matrix. Int. J. Pharm. 2008, 361, 26-32. [CrossRef] [PubMed]

187. Sharma, V.C.C.S.; Deora, A.S. Drug loading and release properties of ionexchange resin complexes which preparedby batch process. J. Drug Deliv. Ther. 2014, 4, 66-73.

188. Umamaheshwari, R.B.; Jain, S.; Jain, N.K. A new approach in gastroretentive drug delivery system using cholestyramine. Drug Deliv. 2003, 10, 151-160. [CrossRef]

189. Murphy, C.S.; Pillay, V.; Choonara, Y.E.; du Toit, L.C. Gastroretentive Drug Delivery Systems: Current Developments in Novel System Design and Evaluation. Curr. Drug Deliv. 2009, 6, 451-460. [CrossRef]

190. Laurent, S.; Bridot, J.L.; Elst, L.V.; Muller, R.N. Magnetic iron oxide nanoparticles for biomedical applications. Future Med. Chem. 2010, 2, 427-449. [CrossRef]

191. Muthu, M.S.; Leong, D.T.; Mei, L.; Feng, S.S. Nanotheranostics—application and further development of nanomedicine strategies for advanced theranostics. Theranostics 2014, 4, 660-677. [CrossRef]

192. Li, S.; Lin, S.; Daggy, B.P.; Mirchandani, H.L.; Chien, Y.W. Effect of HPMC and Carbopol on the release and floating properties of Gastric Floating Drug Delivery System using factorial design. Int. J. Pharm. 2003, 253, 13-22. [CrossRef]

193. Shalaby, W.S.W.; Blevins, W.E.; Park, K. In vitro and in vivo studies of enzyme-digestible hydrogels for oral drug delivery. J. Control. Release 1992, 19, 131-144. [CrossRef]

194. Klausner, E.A.; Lavy, E.; Barta, M.; Cserepes, E.; Friedman, M.; Hoffman, A. Novel gastroretentive dosage forms: Evaluation of gastroretentivity and its effect on levodopa absorption in humans. Pharm. Res. 2003, 20, 1466-1473. [CrossRef] [PubMed]

195. Gaikwad, V.; Yadav, V.; Gaikwad, M. Novel sustained release and swellable gastroretentive dosage form for ciprofloxacin hydrochloride. Int. J. Pharm. Investig. 2014, 4, 88-92. [CrossRef] [PubMed] 
196. Zentner, G.; Park, J.S.; Liu, F. Polymer Blends that Swell in an Acidic Environment and Deswell in a Basic Environment. U.S. Patent 6730327, 3 May 2004.

197. Sandri, S.R.; Bonferoni, M.C.; Ferrari, F.; Mori, M.; Caramella, C. The role of chitosan as a mucoadhesive agent in mucosal drug delivery. J. Drug Deliv. Sci. Technol. 2012, 22, 275-284. [CrossRef]

198. Darandale, S.S.; Vavia, P.R. Design of a gastroretentive mucoadhesive dosage form of furosemide for controlled release. Acta Pharm. Sin. B 2012, 2, 509-517. [CrossRef]

199. Dey, S.K.; De, P.K.; De, A.; Ojha, S.; De, R.; Mukhopadhyay, A.K.; Samanta, A. Floating mucoadhesive alginate beads of amoxicillin trihydrate: A facile approach for H. pylori eradication. Int. J. Biol. Macromol. 2016, 89, 622-631. [CrossRef] [PubMed]

200. Bera, H.; Kandukuri, S.G.; Nayak, A.K.; Boddupalli, S. Alginate-sterculia gum gel-coated oil-entrapped alginate beads for gastroretentive risperidone delivery. Carbohydr. Polym. 2015, 120, 74-84. [CrossRef] [PubMed]

201. Liu, Y.; Zhang, J.; Gao, Y.; Zhu, J. Preparation and evaluation of glyceryl monooleate-coated hollow-bioadhesive microspheres for gastroretentive drug delivery. Int. J. Pharm. 2011, 413, 103-109. [CrossRef] [PubMed]

202. Karemore, M.N.; Bali, N.R. Gellan gum based gastroretentive tablets for bioavailability enhancement of cilnidipine in human volunteers. Int. J. Biol. Macromol. 2021, 174, 424-439. [CrossRef] [PubMed]

203. Paul, S.D.; Sharma, H.; Jeswani, G.; Jha, A.K. Chapter 12-Novel gels: Implications for drug delivery. In Nanostructures for Drug Delivery; Andronescu, E., Grumezescu, A.M., Eds.; Elsevier: Amsterdam, The Netherlands, 2017; pp. 379-412. [CrossRef]

204. Chiriac, A.P.; Ghilan, A.; Neamtu, I.; Nita, L.E.; Rusu, A.G.; Chiriac, V.M. Advancement in the Biomedical Applications of the (Nano)gel Structures Based on Particular Polysaccharides. Macromol. Biosci. 2019, 19, 1900187. [CrossRef]

205. Kundu, B.; Brancato, V.; Oliveira, J.M.; Correlo, V.M.; Reis, R.L.; Kundu, S.C. Silk fibroin promotes mineralization of gellan gum hydrogels. Int. J. Biol. Macromol. 2020, 153, 1328-1334. [CrossRef]

206. Lopez-Heredia, M.A.; Łapa, A.; Reczyńska, K.; Pietryga, K.; Balcaen, L.; Mendes, A.C.; Schaubroeck, D.; Van Der Voort, P.; Dokupil, A.; Plis, A.; et al. Mineralization of gellan gum hydrogels with calcium and magnesium carbonates by alternate soaking in solutions of calcium/magnesium and carbonate ion solutions. J. Tissue Eng. Regen. Med. 2018, 12, 1825-1834. [CrossRef]

207. Abd El-Aziz, M.F.; Ismail, S.; Tadros, M.I.; Elnabarawi, M.A. Alfuzosin hydrochloride-loaded low-density gastroretentive sponges: Development, in vitro characterization and gastroretentive monitoring in healthy volunteers via MRI. Pharm. Dev. Technol. 2020, 25, 566-578. [CrossRef]

208. Guru, P.R.; Nayak, A.K.; Sahu, R.K. Oil-entrapped sterculia gum-alginate buoyant systems of aceclofenac: Development and in vitro evaluation. Colloids Surf. B Biointerfaces 2013, 104, 268-275. [CrossRef]

209. Abd El Hady, W.E.; Soliman, O.A.E.; El Sabbagh, H.M.; Mohamed, E.A. Glutaraldehyde-crosslinked chitosan-polyethylene oxide nanofibers as a potential gastroretentive delivery system of nizatidine for augmented gastroprotective activity. Drug Deliv. 2021, 28, 1795-1809. [CrossRef]

210. Schneider, F.; Koziolek, M.; Weitschies, W. In Vitro and In Vivo Test Methods for the Evaluation of Gastroretentive Dosage Forms. Pharmaceutics 2019, 11, 416. [CrossRef] [PubMed] 